\title{
The concept of urban intensity and China's townization policy: Cases from Zhejiang Province
}

\section{Citation}

Guan, ChengHe, and Peter G. Rowe. 2016. “The Concept of Urban Intensity and China's Townization Policy: Cases from Zhejiang Province." Cities 55 (June): 22-41. doi:10.1016/ j.cities.2016.03.012.

\section{Published Version}

doi:10.1016/j.cities.2016.03.012

\section{Permanent link}

http://nrs.harvard.edu/urn-3:HUL.InstRepos:33980524

\section{Terms of Use}

This article was downloaded from Harvard University's DASH repository, and is made available under the terms and conditions applicable to Open Access Policy Articles, as set forth at http:// nrs.harvard.edu/urn-3:HUL.InstRepos:dash.current.terms-of-use\#OAP

\section{Share Your Story}

The Harvard community has made this article openly available.

Please share how this access benefits you. Submit a story.

Accessibility 


\title{
The Concept of Urban Intensity and China's Townization Policy: Cases from Zhejiang Province
}

\author{
ChengHe Guan*and Peter Rowe
}

Department of Urban Planning and Design, Graduate School of Design, Harvard University, 48 Quincy Street, Cambridge, MA 02138, USA

* Corresponding author email: cguan@gsd.harvard.edu

\begin{abstract}
Urban intensity, in this paper, is measured by four related concepts: compactness, diversity, density, and connectivity. Together they lead to a single idea when considering spatial distributions potentially in a virtuous manner with regard to resource consumption, economic opportunity, social integration and environmental performance. The methodologies applied here included Moran's I, Shannon's index entropy, and accessibility isotimelines, which were then applied to real case scenarios in 20 towns in Zhejiang Province, selected based on their economic performances, population sizes, and geographical locations. Further inspection discovered that density, an outcome of urban form, is highly correlated to compactness, leading to its elimination. The results showed that among the varying spatial arrangements of urban activities, building footprints and infrastructural elements characterized by monocentric centers of use inscribed with welldefined and relatively uniform grids of streets and related networks, alongside of relatively integrated zones of use, seemed to perform best with regard to urban intensity. At the other end of the morphological spectrum, towns with sharp separations of uses and zones of development, often resulting in overall bifurcation of a town's spatial layout, performed less well. Also, linear forms for small towns were less favorable.
\end{abstract}

Keywords: urban intensity; spatial form; compactness; diversity; density; connectivity 


\section{Introduction}

Amid the forces that shape urban formation in cities and towns, some measure of urban intensity appears to be useful when considering resulting spatial distributions in a potentially virtuous manner with regard to resource consumption, economic opportunity, social integration and environmental performance. Further, such a measure can be comprised of four related spatial concepts. They are compactness, density, diversity and connectivity. Although it might have other dimensions in relative terms, these spatial concepts are the most representative components of urban intensity (Rowe, 2014)._Here, the idea of compactness implies an overall built footprint that is conservative in perimeter and, therefore, less invasive of arable land, conservation areas, and surrounding settlements. Density, often measured simply as the number of inhabitants or dwelling units per area of urbanization, is probably favoured in higher rather than lower degrees in order to lessen wasteful spread and to heighten potential spatial connections among activities. Diversity, akin to its biological application, concerns the type, range, mix and spatial arrangement of urban functions and would also seem to produce fortuitous results at higher rather than lower levels. Similarly, connectivity concerned with the interaction among two or more spatial entities within an urban area seems to produce better results also when high rather than low, whether measured by spatial proximity, physical access and administrative or cultural distance. Finally, all four concepts may be combined into a single idea and measures of urban intensity. The goal of this paper is to use the concept of urban intensity to ascertain which kind of morphological spatial distributions perform better for mid- to small-sized cities in China's Changjiang Delta.

\section{Inherent Paradoxes}

There is ample empirical evidence alongside of hypothetical comparisons, however, indicating that such uniformly upward alignments of performance across all four measures of urban intensity may not yield the best results (Rowe, 2014). Compactness and monocentric high density, for instance, can result in overcrowding, dilapidation and congestion. Diversity may run into several paradoxes. There is a version of Marshall's dilemma, for example, where economic participation by many enterprises may preserve and even enhance the competitive vitality of an urban area or aggregation of urban functions, but a subsequent well-scaled economy may actually require a single 
dominant enterprise in order to become more fully realized (Marshall, 1920). In addition, Porter and others have stressed that useful diversity is more than simply the aggregation of different enterprises but also requires synergy among them so that they amount in performance to something greater than the sum of the parts (Porter, 2008). Then too, empirical evidence from urban areas shows that mixing functions in locations that are either very high or very low usually both result in inter-district travel that is relatively high, together with associated air pollution and congestion (Hong \& Li, 2009). Also, geographic accessibility can become misleading through overcrowding of roadways and subway lines, for instance, in the absence of other alternative modes of transportation and routes of travel. In short, urban intensity generally involves 'sweet spots' and non-linear relations among the four underlying concepts and their combination (Rowe, 2014). Indeed, in Zhejiang Province, the performance of towns provides further empirical evidence that a well-balanced combination of density, compactness, diversity, and connectivity exhibits superior outcomes in urban formation.

\section{Cases of Urban Intensity in Zhejiang Province}

The concept of urban intensity was applied to 20 small cities and towns in Zhejiang Province as part of a study aimed more broadly at bench marking communities below the level of larger urban circumstances with regard to contributions that might or might not be made to sustained development, quality of life and domestic consumption (Town Development Data Research Institute, 2015). This also coincides with at least one of the thrusts of China's new townization policy explicitly concerned with upgrading the quality of inhabitant's urban experience in a manner that presents a real alternative to life in a big city (Central Government of the People's Republic of China, 2014). China's new townization policy, elevated to a national strategy in 2013 by Premier Li Keqiang, was developed in order to secure a better future for smaller city and town dwellers, particularly with regard to community, consumer, and lifestyle services, as well as environmental sustainability. In so doing, the policy will also potentially alleviate migration into large cities in China.

\section{a. Study Area}

Zhejiang Province located on the east coast of People's Republic of China is bordered by Jiangsu Province and Shanghai municipality to the north, Anhui and Jiangxi Province to the west, and Fujian Province to the south. It covers an area of 101,800 
$\mathrm{km} 2$ with a density of 540 people per $\mathrm{km} 2$, and includes eleven prefecture level cities, 90 counties, and 1570 townships (People's Government of Zhejiang Province, 2015). Its gross domestic product has been ranked among the top five since 1995 and, as one of the most economically developed areas in China, the province has also played an important role in the townization process proposed by the central government during the $18^{\text {th }}$ plenary session of standing committee. In fact, the selection of towns was based on a previous study of economically promising locations, most of them distributed in the northeast region of Zhejiang province (Central Government of the People's Republic of China, 2013). In short, Zhejiang Province is a good place to examine smaller city and town development because its relatively advanced socio-economic circumstances represent the likely present-future of China. Also, the larger city structure in the province embraces a number of significant smaller settlements. Moreover, with a range from sizable cities like Hangzhou and Ningbo, useful scale comparisons are presented.

More specifically, among the 20 towns, five are in Hangzhou, four in Ningbo, three in Huzhou and Jiaxing, two in Taizhou, and one each are in Jinhua, Shaoxing, and Wenzhou (Figure 1). The residential population ranges from 396,000 in Longgang to 55,049 in Fenshui. Towns are also distributed in different geographical circumstances: Eight are in riverine areas, four in mountain valleys, three in peri-urban conditions, two in coastal and deltaic zones, two in plains, and one - Guali - adjacent to a regional airport. Xindeng, one of the mountain valley towns, for example, is the sub-center of Fuyang district in Hangzhou, and occupies $180 \mathrm{~km}^{2}$ of land. It was selected by the National Development and Reform Commission to be in the first round of experimental towns for redevelopment (Fuyang Government of Hangzhou, 2015). Fenshui, a subcenter for Tonglu County, is also a mountain valley town located in the western part of Hangzhou. The $133.1 \mathrm{~km}^{2}$ administrative area carries a strong linear form. Guali ranked as one of the top one hundred towns in China, has a history traceable back to 978 A.D. Now, under the slogan 'small town big dream', a catchphrase to promote small- to midsized towns' urbanization, it is moving forward with new industrialization and tertiary sector development (Guali Government of Hangzhou, 2015). Qiandaohu, a riverine town in Chun'an County, is a tourist destination renowned for its man-made lakes. Tangqi is currently the second largest town in Yuhang and also a riverine town located ten kilometers away from downtown Hangzhou. In Shaoxing, Simen and Zhouxiang are in peri-urban conditions, Shipu is located on the coastline, and Xikou is in a mountain valley. Zhili occupies $135.8 \mathrm{~km}^{2}$ of land area in Huzhou and two thirds of its 
populations were non-registered migrants, representing a typical peri-urban condition in the city. Lianshi and Xinshi are both located in riverine conditions in Huzhou and Wangjiangjing and Chongfu are both riverine towns in Jiaxing. Chang'an is another specially selected town in Jiaxing located in a plain area. Zeguo is one of the towns in Wenling, Taizhou, with a population of 192,558 in 2010, half of which were registered residents. Chumen is a riverine town administrated by Yuhuan County of Taizhou. Fotang in a mountain valley is located in the geographical center of Jinhua. Qianqing is a riverine town in a peri-urban condition to Shaoxing and Longgang is a coastal town with the largest population among the selected 20 towns, as mentioned earlier.

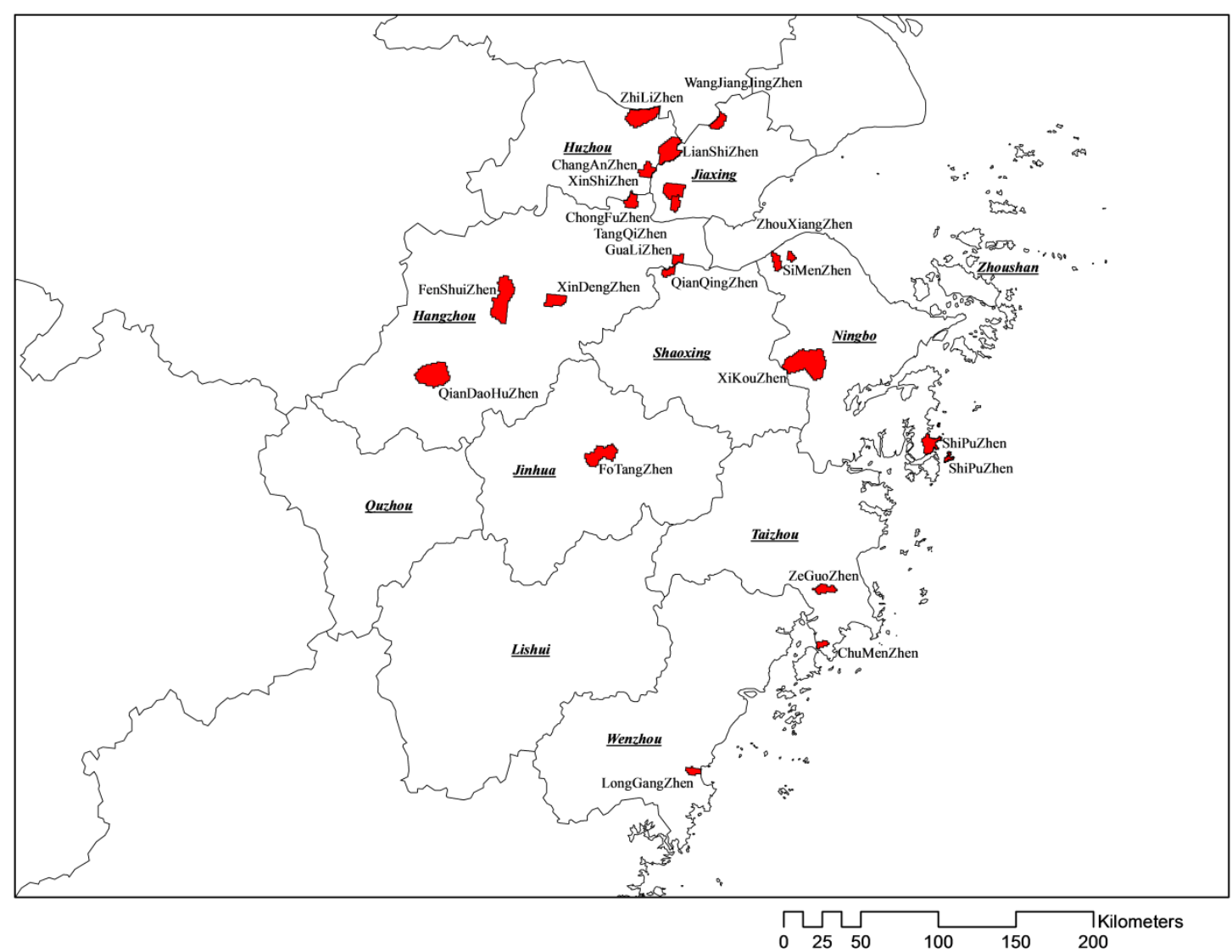

Figure 1, 20 Selected Towns in Zhejiang Province

\section{b. Data Collection}

Data collection methods used in this study included site surveys, satellite image processing, as well as digital library and statistical yearbook searches. Background terrain images were downloaded from both Baidu Maps and World Imagery, an integral part of ArcMap providing one meter or better spatial resolution to satellite and aerial imagery in many parts of the world (World Imagery, 2015). It also covers natural conditions such as rivers, lakes, reservoirs, mountain valleys, hills, and coastlines. Data 
about streets were acquired from Open Street Map (OSM) and the Detailed Control Plans at various administrative levels. OSM has a function that allows the conversion of vector data in a compatible format to be downloaded and used in ArcMap. The Detailed Control Plans of the townships, varying by city from 2009 to 2015, were scanned at 600dpi high resolution and then georeferenced to ArcMap allowing the overlay of background terrain images. Built-up areas were extracted from satellite images using remote sensing techniques. Both supervised and unsupervised methods were applied by two groups of personnel independently. The results were comparable revealing less than $5 \%$ error during the coding process and there appeared to be no significant biases in the supervised process. Commercial streets and business activities were compiled based on extensive site surveys and Baidu Maps. Each of the commercial shops and stores were surveyed according to their spatial location between intersections of streets and then numbered and categorized yielding as many as 1,000 commercial outlets per town.

\section{Methodology}

The study area was first divided into square grid cells of 500 meters by 500 meters, roughly corresponding to the scale of mega plots for development and discrimination of sufficient detail from satellite image implementation (Figure 2). The purpose of the cell division is to provide a consistent study object for measurement and comparison of urban intensity scores across the selected towns. This method has been applied commonly in other studies of spatial analysis (Yoon \& Srinivasan, 2015). The World Imagery, for instance, provided 500 meters resolution for imagery at a small scale, where each pixel represented a five meter by five meter ground distance. It could also be adjusted for spatial accuracy to avoid spatial distribution errors (Read et al, 2011; Comber, 2012). Nevertheless, excessive aggregation within the study area could lead to the Modifiable Areal Unit Problem (MAUP), described by Openshaw as a source of statistical bias (Openshaw, 1983). On the other hand, too fine a grained grid couldn't be supported by the data sources. Under such considerations 500 meter grid cells were chosen as the most appropriate scale of representational resolution. With this in mind, there were two scales to each town's research area. The first was universal for all 20 towns, each containing 432 grid cells and not corresponding exactly to the actual administrative area of the towns. For example, Figure 3 shows 432 grid cells which correspond to $108 \mathrm{~km}^{2}$, while the actually boundaries of the towns covered $126.92 \mathrm{~km}^{2}$, $180 \mathrm{~km}^{2}$, and $133.1 \mathrm{~km}^{2}$, respectively, for Guali, Xindeng, and Fenshui. The 
administrative areas show Guali and Fenshui have comparable dimensions. However, in reality, Guali has a much larger urban area than Fenshui. Thus, a second study area was established, which was town specific and better represented the actual urban conditions. For example, there were 234 grid cells in Chang'an containing urban footprints out of the 432 grid cells in total, the other 198 were farm land, forests, lakes, and natural reserves (Appendix 1).

Using the universally scaled study area, background data were acquired through OSM with layers representing streets, roads, rivers, hills, and other natural and manmade features. Throughout, the World Geodetic System 1984, also known as WGS84 Geographic Coordinate System (GCS), was used (Zhejiang Administration of Surveying, 2015). The Projected Coordinate System (PCS) was the Google Mercator System, or GMS. All data that were not projected under GMS were converted to match GMS. They were then aligned with corresponding layers of ArcMap shape files.
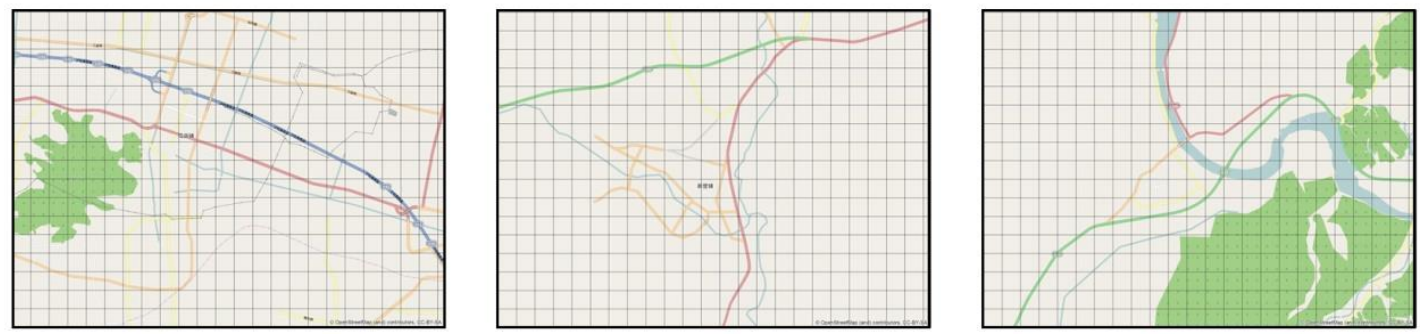

Figure 2: 432 grid cells in the size of 500 meters by 500 meters overlaying with Open Street map. From left to right are sample towns Guali, Xindeng, and Fenshui
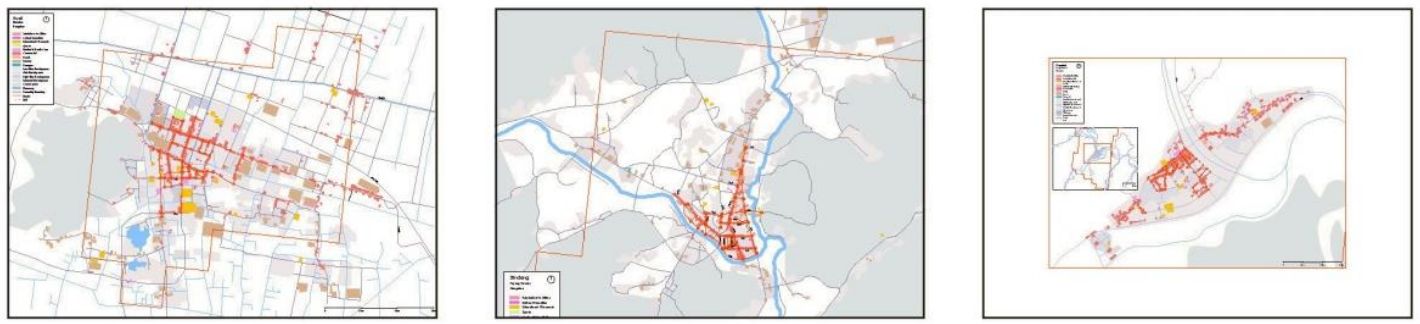

Figure 3, Background map with information from site survey and Baidu map registration. From left to right are sample towns Guali, Xindeng, and Fenshui

Formulation of the four measures intrinsic to the concept of urban intensity proceeded in the following manners. Also described is the way in which composite scores for urban intensity were defined. 


\section{(i) Compactness}

Compactness is an attribute that describes urban form (Kropf, 2009). As distinct from spread and sprawl, compactness is a property based on the notion of Euclidean space being closed (Tsai, 2005). It can be measured by Moran's coefficient as follows:

$$
\begin{aligned}
& I=\frac{N}{\sum i \sum j W i j} \frac{\sum i \sum j w i j(X i-X)(X j-\bar{X})}{\sum i(X i-\bar{X}) 2} \\
& \text { Xi: population or value in sub area } i \\
& X j: \text { population or value in sub area } j \\
& X: \text { mean of population or value } \\
& \text { N: number of sub area } \\
& \text { Wij: weighting between sub areas } i \text { and } j
\end{aligned}
$$

A higher Moran's I corresponds to a monocentric form and a lower number for a decentralized form (Tsai, 2005; Rowe, 2013). Wij is the weighting coefficient that defines neighborhood conditions. The weight matrix behind Wij utilizes the inverse distance spatial relationship to allow nearby features to have a larger influence and the distance method, also behind $\mathrm{Wij}$, was the straight line Euclidean distance. $\mathrm{N}$ is the number of grid cells chosen for each town.

In this research, compactness was reflected in the form of urban built-areas and their spatial distribution. Simply put, a town with most of its built-up area concentrated around its town center will have a more compact urban form. On the other hand, a town that shows a pattern of built and unbuilt area next to each other will have a decentralized form. Instead of residential population, $\mathrm{Xi}$ and $\mathrm{Xj}$ were used as percentages of occupation by built-up area for each grid cell. Weighting was treated equally among all cells. In this study, compactness was restricted to two-dimensional measures, without consideration of third dimensional variations which were likely to be reflected by density. In fact, the field surveys indicated that third dimensional variations were few and far between among the towns and of little consequence.

\section{(ii) Diversity}

Both Shannon's index and the Gini index are good indicators of diversity. Often the Gini index is applied to income inequality of populations (White, 1986). On the other 
hand, Shannon's index is best used for typological and biological applications such as needed here (Fujita, 1999; Song 2004; Kashem, 2009). Shannon's index can be calculated in the following method:

$$
\begin{aligned}
& H=-\sum_{i=1}^{R} p i(\ln p i) \\
& H=\text { Shannon index } \\
& p i=\text { fraction of the entire population made up of group } i \\
& R=\text { number of total groups } \\
& \ln =\text { natural logarithm } \text { with the base e }(e=2.71828 \ldots)
\end{aligned}
$$

$H$ represents the Shannon's index of entropy, proposed to quantify the abundance in the string of interest, in this case the diversification of building types. A larger Shannon number means a more diverse arrangement and a smaller Shannon number means a less diverse arrangement. However, there is no fixed standard to evaluate Shannon's index numbers. In this research, diversities were transformed to normalized numbers for comparative purposes. $R$ is the number of total groups or building types. The classification was based on local building-code and land-use regulations. Sub-groups were not included, giving rise to seven categories: office, commercial, residential, industrial, government and social service, green field and water, and others. The fraction of each building type was represented by $p i$.

The population of buildings was defined by the function of the buildings, instead of their zoning assignment, to reflect the finer-grained mixture of structures. Each grid cell was measured by the majority occupation of the building function within the area. The method for measurement was of two types: Machine counting and visual inspection. Machine counting used the data in the AutoCAD format, which was then converted to vector shape files operable in a Geographic Information System environment. The shape files were georeferenced into an ArcMap files with the same georeferenced system, namely: Google Mercator. Each shape file was matched with its associated grid cells and the percentage of occupation was calculated. Visual inspections used the same base material and were counted by trained personnel. This allowed a check to be made on any significant errors or data losses. 


\section{(iii) Density}

Density was calculated by population divided by land area. In this research, the unit used for land area was accounted for by grid cell and the population was resident population in lieu of registered population. The formula used was as follows:

$$
\begin{aligned}
& D=P_{r} /\left(N_{g} * 0.25 \mathrm{~km}^{2}\right) \\
& D=\text { Density } \\
& P r=\text { Resident Population } \\
& N g=\text { Number of Grid Cells }
\end{aligned}
$$

In the statistical year books and many other forms of statistical data, the administrative boundaries were used to compute density. However, the administrative boundaries were often arbitrary and not able to accurately convey local conditions. The unit for $D$ is the number of people per quarter square kilometer, corresponding to the size of a grid cell. $\operatorname{Pr}$ is the resident population, which differed from registered population. Indeed, in all the towns under study, the resident population was larger than the registered population.

\section{(iv) Connectedness}

Connectedness, as such, can be defined in a number of ways as alluded to earlier. For instance, it is common practice to use 'accessibility' as a method to represent connectedness. In this research, a gravity model formula was used to calculate both physical distance and social measures as follows:

$$
\begin{aligned}
& \text { Ati }=\sum_{j=1, n} A i j=\frac{p i+p j}{d_{i j}^{e}} \text { where } e=2 \\
& \mathrm{P}=\text { population } \\
& \mathrm{A}=\text { Accessibility } \\
& \mathrm{At}=\text { Attractiveness } \\
& \mathrm{D}=\text { distance } \\
& \mathrm{N}=\text { number of spatial units }
\end{aligned}
$$

Further, to measure accessibility in this formulation, it was necessary to define four destinations. They were commercial centers, employment centers, government centers, 
and major highway junctions. The coefficients assembled with each were then assumed to be equal to one:

$C=a^{*} \operatorname{Com}+b^{*} E m p+c * T r a+d^{*}$ Gov $\quad a, b, c, d=1$

C: connectedness measured by accessibility

Com: Commercial center

Emp: Employment center

Tra: highway conjunction

Gov: Government center

$a, b, c, d$ : coefficient

Accessibility maps were generated individually. Using commercial centers as an example, first, Baidu Map business registrations and site surveys were conducted to produce a map with a comprehensive list of commercial enterprises and their locations. Based on these locations, a cluster analysis was performed to find where the agglomerations were most visible and the location for each cluster was identified, leading to the tracing of centers. Each center then became a destination. The next step was to find isotimelines in the study area, including conversion of streets from vector to raster files. The properties of the raster files were then assigned a travel speed. This specific number, also called 'time speed', was then assigned to the raster. Once all cells received a travel speed, calculations were made regarding the time cost to destinations. Isotimeline maps were then created.

Then, within a five minute travel time zone, each cell was assigned either a value of one, meaning it was accessible, or zero meaning it was not. The values were summed up across the four destinations and the higher the value the more generally accessible was the cell location.
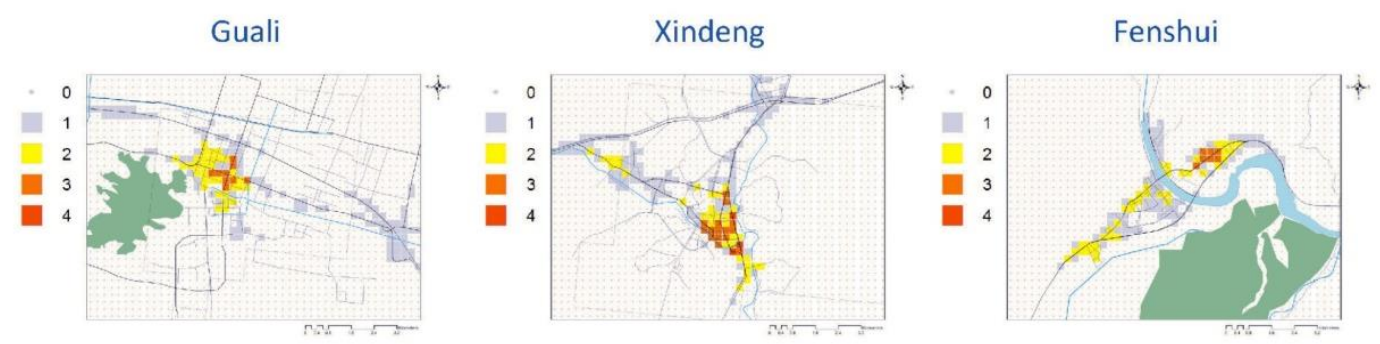

Figure 4, Accessibility study results of sample towns Guali, Xindeng, and Fenshui, from left to right 


\section{(v) Composite scores}

The composite scores were the sum up of all four urban intensity variables and were expressed as:

$$
S_{i}=W_{j} \sum_{j=1}^{n} \ln \left(\frac{X_{j}}{\bar{X}_{J}}\right)
$$

where $W j=1$

Si: Composite Score of town $i$

Wj: Weight of variable $j$

$n$ : Number of variables, $n=4$

Xj: Compactness, Diversity, Density, and Connectivity

$\bar{X}_{J}:$ Mean of variables

Natural-log values were applied in lieu of the raw number of the scores, because this practice can distribute the data in a more regulated pattern, bring the different components to the same scale range, and eliminate the impact of potential outliers. The variables were given equal weight to reflect this equal importance in general to urban form, and not to answer specific questions. In this last regard, for example, connectivity might be weighted more than others, if the research question was a study of the transit accessibility.

Removing density as a factor, the formula, for the composite score was updated using three variables: Compactness, diversity, and connectivity as follows:

$$
S_{i}=W_{j} \sum_{j=1}^{n} \ln \left(\frac{X_{j}}{\bar{X}}\right)
$$

$$
\begin{aligned}
& \text { where } W j=1 \\
& \text { Si: Composite Score of town } i \\
& \text { Wj: Weight of variable } j \\
& n: \text { Number of variables, } n=3 \\
& X j: \text { Compactness, Diversity, and Connectivity } \\
& \bar{X}_{\mathrm{J}}: \text { Mean of variables }
\end{aligned}
$$


The selection of each methodological calculation of the measures of urban intensity was aimed to better serve the purpose of spatial analysis. Also, the independent structure of equations could produce results for measures comparable to those in other studies.

\section{Results}

With respect to compactness Moran's I ranged from 0.1912 to 0.7851 . These were global statistics assuming homogeneity and yielded the spatial autocorrelation for the whole area. The $\mathrm{p}$ values were all significant for the 20 towns based on expected index values, and the results showed clusters within the study area. None of the towns involved random spatial distributions but were planned under certain jurisdictional and government powers. Guali, Fenshui, and Chongfu were the top three towns in this regard, showing the most clustered patterns.

Diversity measured by Shannon Entropy values was topped by Xindeng at 5.942, dropping to 4.490 for Wangjiangjing. The classifications in the diversity index, as explained in the methodology section, included seven categories. Further breakdown of these categories into sub-categories, based on Shannon entropy, was tested on a small sample. However, results from this test failed to discriminate among the towns to the same extent as the seven categories and was not pursued further. Overall, the formula frequency of the Shannon Index ranged from 130 for a small footprint town like Fenshui, to 378 for large footprint town like Zhili. Xindeng was an exception with a long diagonal axis which pushed the frequency high although the actual built area was comparatively small.

Density calculated as population per grid cell reflected the density of urban occupied areas, excluding farmland and natural features. Longgang had the highest density, but with a large population which was more than twice that of any other town in the study. Besides Longgang, Zhouxiang had the highest density and Xindeng the lowest.

Connectivity scores had a wide range from Xikou's 113 to Chongfu's 303 points with a mean of 243.7 points. Chongfu's score comprised of commercial at 53, transit at 39, government at 115, and employment at 96, revealing that, around the government center, there were land parcels well utilized for residential or commercial purposes. However, the relatively low transit score of 39 showed that the connection to the outside 
was not high. Among the 20 towns, there were nine that had equal accessibility within both study areas described earlier. The other eleven had different scores but the gaps were not significant. The largest gap between the two study areas was Simen at 82 (Appendix 2c). The explanation for this was twofold: sparsely-located employment and/or remotely-located factories, both separated from the main township area.

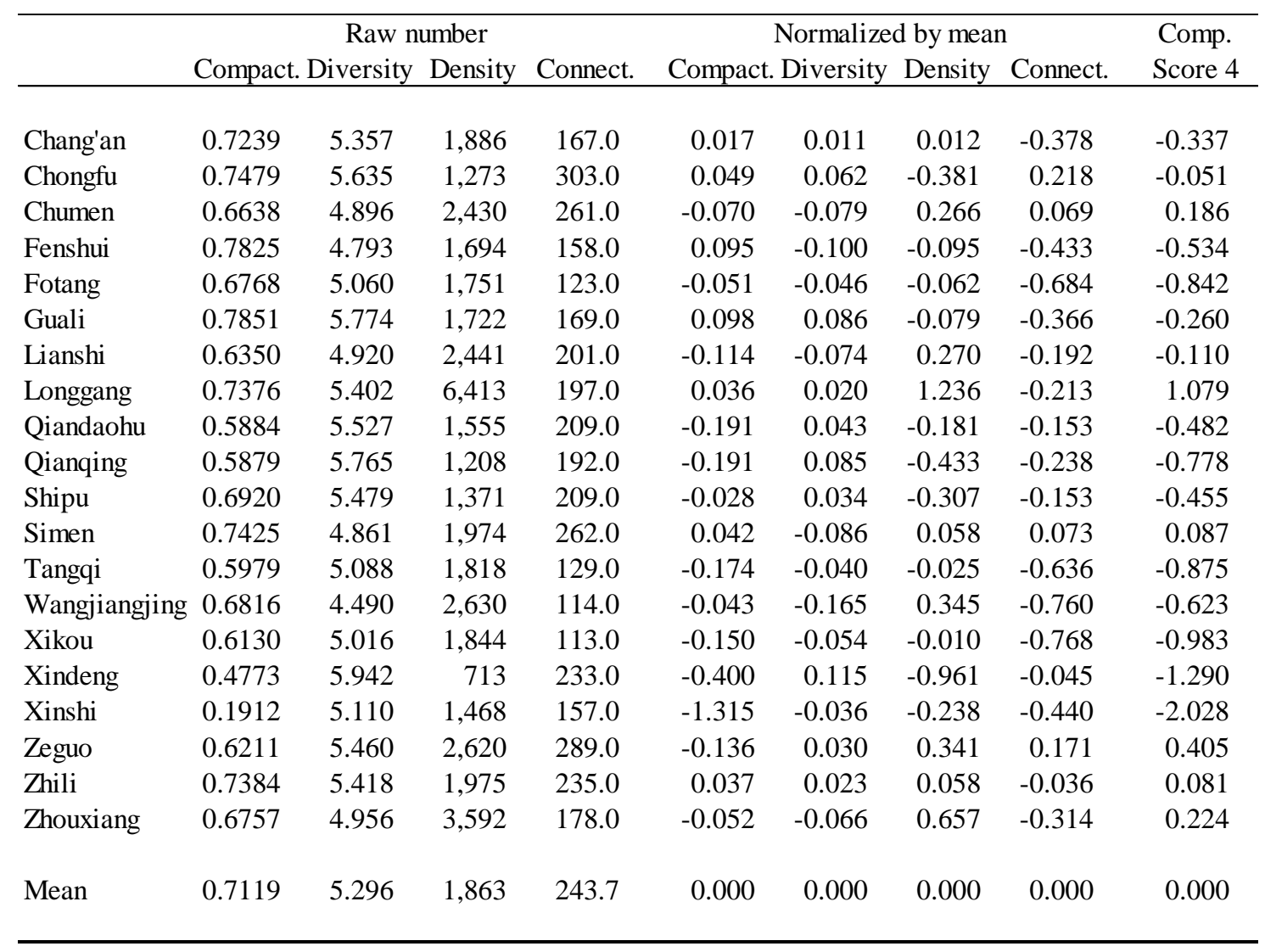

Figure 5, Composite scores for measure of urban intensity

The raw numbers for compactness, diversity, density and connectivity were all normalized using the same method. This involved division by the mean of each group of variables and then normalization through their natural logarithmic values (Figure 5, Composite Score 4). The purpose of the composite score was to reveal the balanced development of urban form in general and not to emphasize one characteristic over the others. Hence, the weights for all four variables were evenly distributed. One of the disadvantages of composite scores is inclusion of variables with highly positive correlations. Figure 6 shows the correlations between variables, with density and compactness highly correlated at 2.665 , essentially meaning one can be explained by the other to a large extent. Among the other combinations of factors, correlation was relatively low, and, therefore, they could be considered to be acting independently. 


\begin{tabular}{|l|r|r|r|r|}
\hline & Compactness & Diversity & Density & Connectivity \\
\hline Compactness & 1.0000 & - & - & - \\
\hline Diversity & -0.0750 & 1.0000 & - & - \\
\hline Density & 2.6650 & -0.2430 & 1.0000 & - \\
\hline Connectivity & 0.1444 & 0.4008 & -0.0298 & 1.0000 \\
\hline
\end{tabular}

Figure 6, Correlation between variables

The results of the composite score for the second run by eliminating density as a variable are shown in Figure 7, and the following observations can be made regarding the two scores: First, Longgang dropped from top to seventh place. Based on the 2010 resident population, Longgang tops the 20 towns by a large margin, being more than twice as big as the second largest town Zeguo which has 192,558 residents. In the second-round results, apart from density, Longgang's performance was not outstanding. In the absence of density, Longgang's performance closely resembled that of other towns across the three variables and the composite score. Indeed, the case of Longgang unveiled the importance and sometimes misleading aspects of score aggregation and particularly amid towns of very different sizes, arguing for a range that was more comparably sized. Second, Zhouxiang, dropped from third place to fourteenth place. It was also among the group with the largest population and among others that produced relatively lower efficiencies in terms of compactness, diversity, and connectivity. As for other towns, Chongfu rose in relation with the exclusion of density as did Xindeng. Both exhibit a balance of strong performance across the three variables, and therefore, high composite scores. For planners and policy makers, urban intensity becomes a tool to measure the 'good form' of towns, often equipped with integrated infrastructure, well-adjusted social diversity, and balanced functionality. (Figure 8 and 9) 


\begin{tabular}{lrlrrr}
\hline \multicolumn{1}{c}{ With Density } & \multicolumn{5}{c}{ Without Density } \\
\multicolumn{1}{c}{ Town } & Score & Town & Score & $\Delta$ Rank & $\Delta$ Score \\
\hline 1 Longgang & 1.079 & 1 Chongfu & 0.329 & 6 & 0.381 \\
2 Zeguo & 0.405 & 2 Zeguo & 0.065 & 0 & -0.341 \\
3 Zhouxiang & 0.224 & 3 Simen & 0.029 & 2 & -0.058 \\
4 Chumen & 0.186 & 4 Zhili & 0.023 & 2 & -0.058 \\
5 Simen & 0.087 & 5 Chumen & -0.080 & -1 & -0.266 \\
6 Zhili & 0.081 & 6 Shipu & -0.148 & 5 & 0.307 \\
7 Chongfu & -0.051 & 7 Longgang & -0.157 & -6 & -1.236 \\
8 Lianshi & -0.110 & 8 Guali & -0.182 & 1 & 0.079 \\
9 Guali & -0.260 & 9 Qiandaohu & -0.301 & 3 & 0.181 \\
10 Chang'an & -0.337 & 10 Xindeng & -0.329 & 9 & 0.961 \\
11 Shipu & -0.455 & 11 Qianqing & -0.345 & 4 & 0.433 \\
12 Qiandaohu & -0.482 & 12 Chang'an & -0.350 & -2 & -0.012 \\
13 Fenshui & -0.534 & 13 Lianshi & -0.380 & -5 & -0.270 \\
14 Wangjiangjing & -0.623 & 14 Zhouxiang & -0.433 & -11 & -0.657 \\
15 Qianqing & -0.778 & 15 Fenshui & -0.438 & -2 & 0.095 \\
16 Fotang & -0.842 & 16 Fotang & -0.780 & 0 & 0.062 \\
17 Tangqi & -0.875 & 17 Tangqi & -0.851 & 0 & 0.025 \\
18 Xikou & -0.983 & 18 Wangjiangjing & -0.968 & -4 & -0.345 \\
19 Xindeng & -1.290 & 19 Xikou & -0.972 & -1 & 0.010 \\
20 Xinshi & -2.028 & 20 Xinshi & -1.790 & 0 & 0.238 \\
& & & & & \\
\hline
\end{tabular}

Figure 7: Composite scores for measure of urban intensity

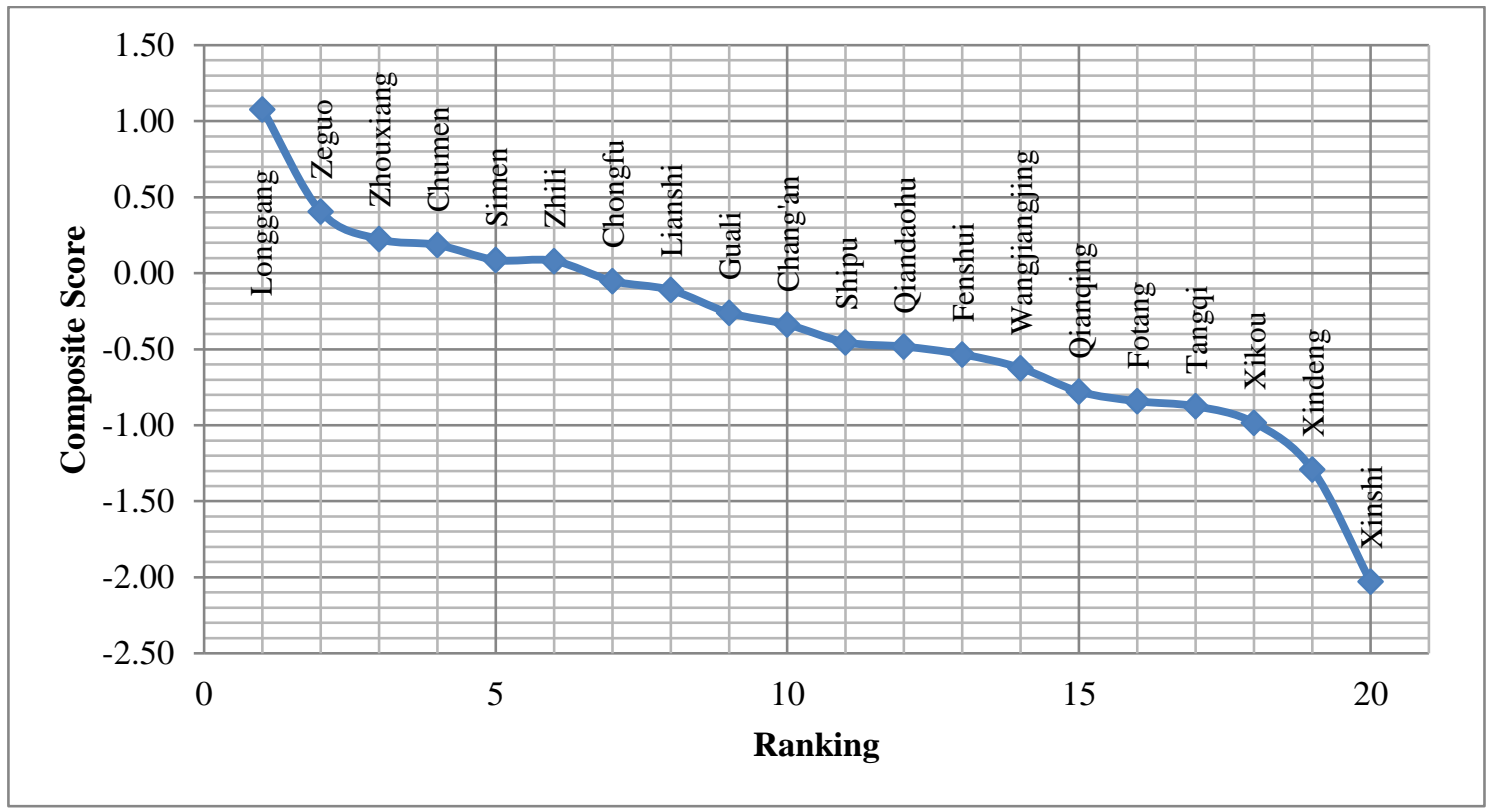

Figure 8: Ranking of 20 towns using composite scores and four variables 


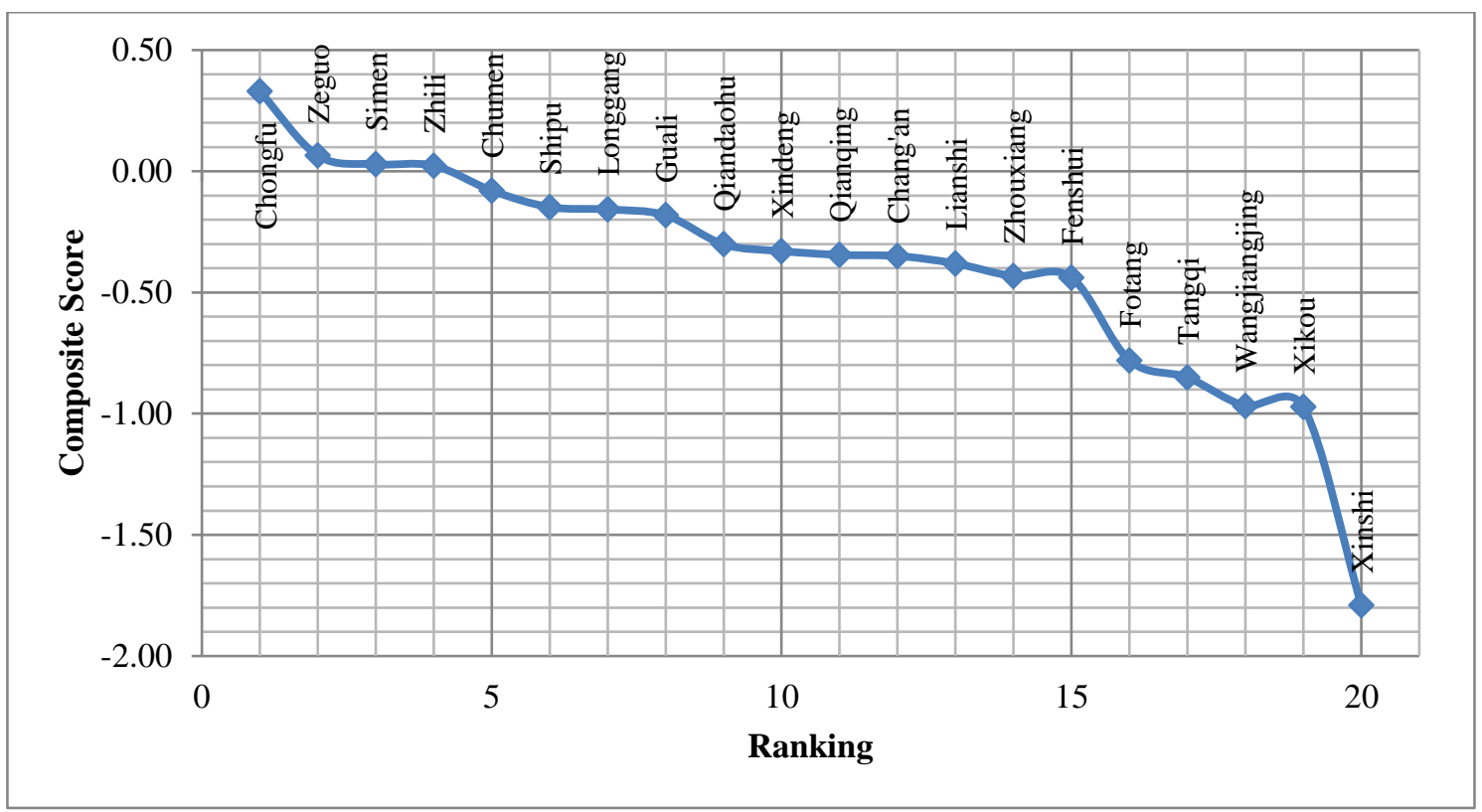

Figure 9: Ranking of 20 towns using composite scores and three variables

The composite scores of urban intensity, in the study area, follow the basic measuring principle of the higher the number the better the performance. Among the 20 towns measured using three variables, relatively normal distributions were exhibited. From the ranking diagram, a pattern of one top city followed by a group of second tier cities, and a few cities falling behind, was observed. The scores were not varying only by the size of the towns or any one single variable. Further, the score of a city was not static but derived relevant to the scope of the region concerned and its relative ranking among other towns there.

\section{Discussion}

This research demonstrates that a concept of urban spatial formation called 'urban intensity' can be compiled from readily and uniformly available data. This concept, in turn, can be empirically estimated to rank order cities and towns according to a balance of high performance across measures that would seem to matter inherently for less wasteful and more efficient spatial arrangements of activities comprised of compactness, diversity and connectivity. At this juncture, however, comparisons and rank ordering across wide ranging scales of small cities and towns would require further investigation, particularly with regard to cross correlations among determinants of urban intensity. Other measures of diversity, compactness and connectivity may also produce somewhat different results. Nevertheless, among the varying spatial arrangements of 
urban activities, building footprints and infrastructural elements, are spatial forms characterized by monocentric centers of use inscribed with well-defined and relatively uniform grids of streets and related networks, alongside of relatively integrated zones of use, that in aggregate appear to perform best. Included here were Chongfu and Zeguo. At the other end of the morphological spectrum, towns with sharp separations of uses and zones of development, often resulting in overall bifurcation of a towns spatial layout, performed less well with regard to urban intensity. These included at least Xinshi, Xikou, Wangjiangjing, Tangqi, Fotang and Fenshui. The remaining towns appear to lie between these two morphological conditions, with towns like Simen, Zhili, Chumen, and Guali being composed of grid-like arrangements of streets and blocks, relatively compact overall forms, and some degree of use integration. In short, they were more like Chongfu and Zeguo. The others, from Xindeng to Zhouxiang appear to be both less clear in their common spatial arrangements.

Speculating beyond these results, it would also seem that well-integrated, gridded monocentric morphologies are more or less optimal spatial formations for medium to small-sized towns, certainly in the range of 50,000 to 200,000 inhabitants. This, in turn, contrasts with the often more favorably regarded polycentric arrangements at higher levels of population size and among so-called mega-cities. Ceteris paribus, linear arrangements of smaller cities and towns would also seem to be less favorable, especially given tendencies in this and other samples towards separation of use zones and often bifurcation of overall spatial formation.

\section{Acknowledgements}

This research is supported by Zhejiang Changjiang Delta Townization Data Research Center (TDDR). 


\section{References}

Arnott, R. (1979). Optimal city size in a spatial economy. Journal of Urban Economics, $6(1), 65-89$.

Batten, D. (1995). Network Cities: Creative Urban Agglomerations for the 21st Century. Urban Studies, 32(2), 313-327.

Boarnet, M. G. (2001). Travel by design: the influence of urban form on travel. (R. Crane, Ed.). Oxford: Oxford University Press.

Central Government of the People's Republic of China. (2013). The $18^{\text {th }}$ plenary session of standing committee. One of the topics is focusing on how to improve a healthy townization system. There are numerous sources in Chinese.

Central Government of the People's Republic of China. (2014). National New Townization Plan (2014-2020) Beijing: Central Government of the People's Republic of China.

Comber, A., Fisher, P., Brunsdon, C., \& Khmag, A. (2012). Spatial analysis of remote sensing image classification accuracy. Remote Sensing of Environment, 127, 237246.

Fujita, M., Krugman, P., \& Venables, A. J. (1999). The Spatial Economy: Cities, Regions, and International Trade. Southern Economic Journal, 67.

Fuyang Government of Hangzhou. (2015). History of Xindeng. http://www.fuyang.gov.cn/ \& http://mzj.fuyang.gov.cn/juanshou/191081.jhtml

Galster, G., Hanson, R., Ratcliffe, M. R., Wolman, H., Coleman, S., \& Freihage, J. (2001). Wrestling Sprawl to the Ground: Defining and measuring an elusive concept. Housing Policy Debate, 12(4), 681-717.

Ghemawat, P. (2013). World 3.0. Global Prosperity and How to Achieve It.

Guali Government of Hangzhou. (2015). History of Guali, Hangzhou. Information acquired from the official website of Guali and Baidu Baike, both in Chinese languages http://guali.xsnet.cn/html/2015/bzgk_0527/6579.html http://www.guali.gov.cn/cn/index.html

Kashem, S. Bin, Chowdhury, T. A., Majumder, J., \& Rahman, A. (2009). Quantifying Urban form: A Case Study of Rajshahi City. Journal of Bangladesh Institute of Planners, 2(December), 39-48.

Kim, S., \& Rowe, P. G. (2012). Does large-sized cities' urbanisation predominantly degrade environmental resources in China? Relationships between urbanisation and resources in the Changjiang Delta Region. International Journal of Sustainable Development \& World Ecology, 19(4), 321-329. 
Kropf, K. (2009). Aspects of urban form. Urban Morphology, 13(2), 105-120.

Lösch, A. (1954). The economics of location. New Haven: Yale University Press.

Lowry, I. S. (1964). A model of metropolis. Santa Monica, Calif.: Rand Corporation.

Openshaw, S. (1984). The modifiable area unit problem. Concepts and Techniques in Modern Geography, 38, 1-41. Retrieved from http://qmrg.org.uk/files/2008/11/38maup-openshaw.pdf

Openshaw, S. (1989). Modifiable Areal Unit Problem. Concepts and Techniques in Modern Geography, 38, 169-174.

People's Government of Zhejiang Province (2015). These numbers are quoted from the official website. They may change as the merging of town level administrative boundaries. http://www.zj.gov.cn/

Radil, S. M. (2011). Spatializing Social Networks: Making Space for Theory in Spatial Analysis. Dissertation.

Read, S., Bath, P., Willett, P., \& Maheswaran, R. (2011). Measuring the spatial accuracy of the spatial scan statistic. Spatial and Spatio-Temporal Epidemiology, 2(2), 69-78.

Rowe, P. G. (2011). Urban Formation in China Since 1950 Seen from Afar. 城市规划 (英文版), (1), 6-14.

Rowe, P. G. (2014). On Shaping the Space of Time in Urban Circumstances. In Wenyi Zhu (Ed.) Urban Design I, Beijing: Tsinghua University Press, 13-34.

Rowe, P., Kan, H. Y., \& Guan, C. (2013). Methodological Notes on the Spatial Analysis of Urban Formation. Cambridge, Mass: Harvard Graduate School of Design

Song, Y., \& Gerrit-Jan, K. (2004). Measuring Urban Form. American Planning Association. Journal of the American Planning Association, 70, 210-225.

Town Development Data Research Institute (2015). Preliminary Qualification of Townships for ULR Development. Hangzhou: Town Development Data Research Institute, February 2015.

Tsai, Y.-H. (2005). Quantifying urban form: compactness versus "sprawl." Urban Studies, 42(1), 141-161.

Wheaton, W. C. (1998). Land Use and Density in Cities with Congestion. Journal of Urban Economics, 43(2), 258-272.

White, M. J. (1983). The Measurement of Spatial Segregation. American Journal of Sociology, 88(5), 1008. 
White, Michael J. (1986). Segregation and diversity measures in population distribution. Population Index 52 (2) (summer): 198-221.

World Imagery. (2015). It includes $15 \mathrm{~m}$ Terra Color imagery at small and mid-scales $(\sim 1: 591 \mathrm{M}$ down to $\sim 1: 72 \mathrm{k})$ and $2.5 \mathrm{~m}$ SPOT Imagery $(\sim 1: 288 \mathrm{k}$ to $\sim 1: 72 \mathrm{k})$ for the world.

http://www.arcgis.com/home/item.html?id=10df2279f9684e4a9f6a7f08febac2a9

Yoon, H. \& Srinivasan, S. (2015). Are they well situated? Spatial analysis of privately owned public space, Manhattan, New York City. Urban Affairs Review, 51(3), 358-380.

Zhejiang Administration of Surveying (2015). The Zhejiang Adminstation of Surveying Mapping and Geoformation has a list of coordinate systems commonly used in Zhejiang Province http://www.zjch.gov.cn/col/col298/index.html

Zhejiang Sheng (China) Tong, ji ju (Ed.). (2011). 浙江统计年鉴 = Zhejiang tongji nianjian. Zhejiang Tong Ji Nian Jian = Zhejiang Tongji Nianjian . 
Appendix

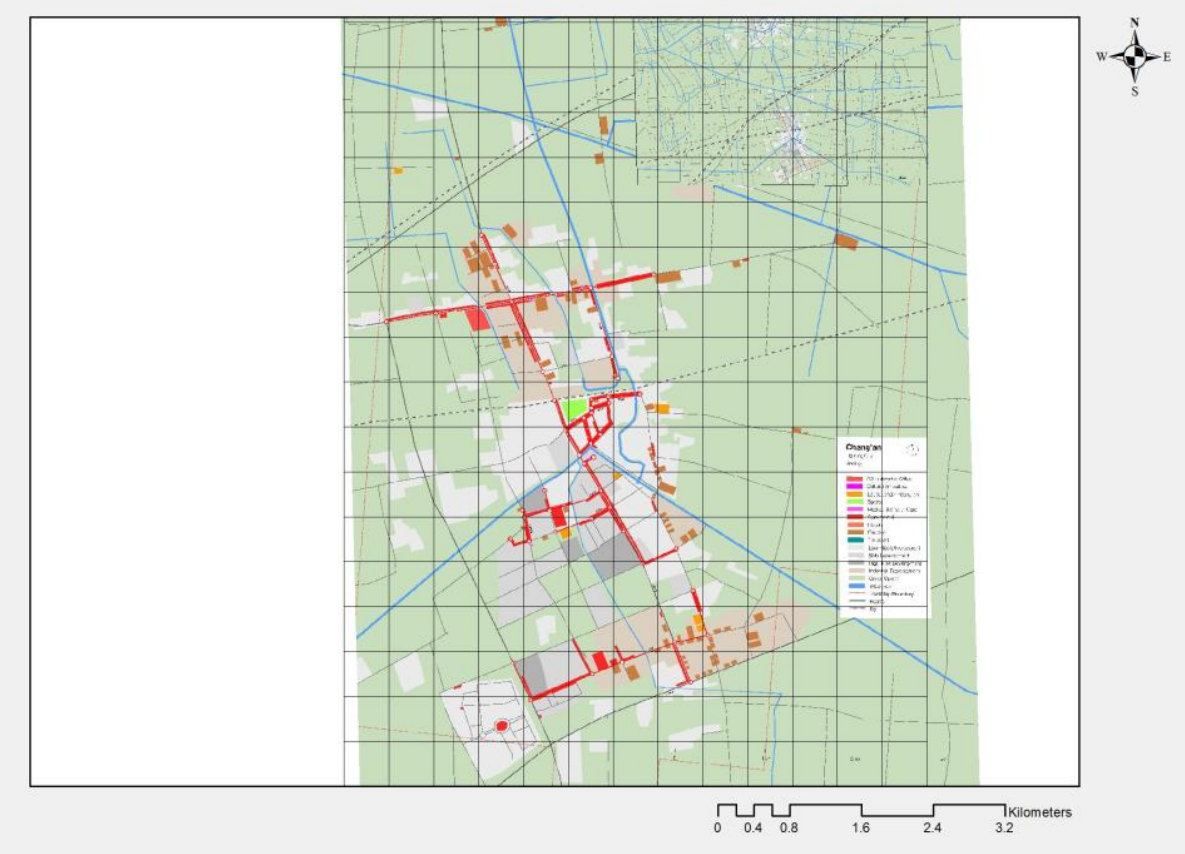

Chang'an
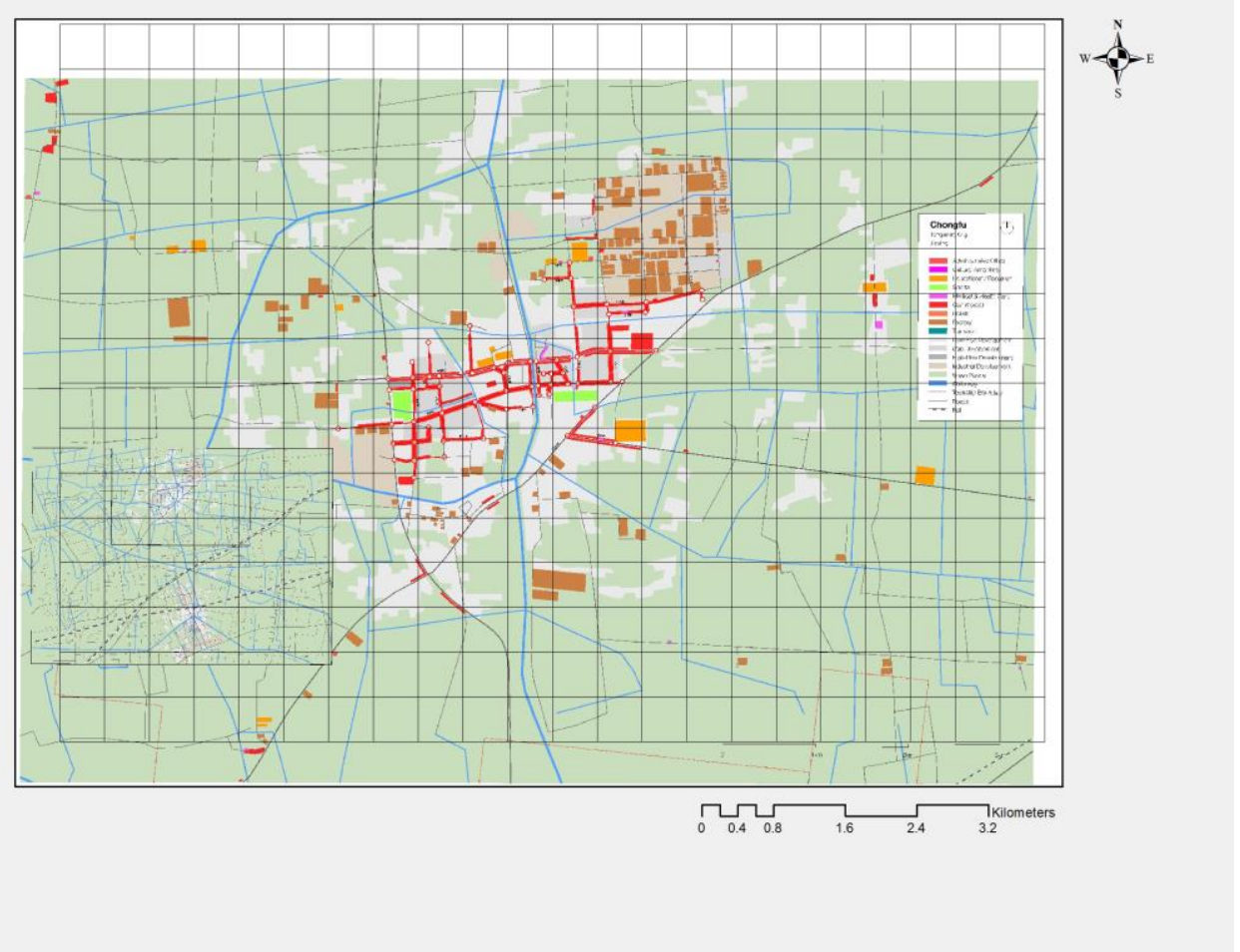

Chongfu 


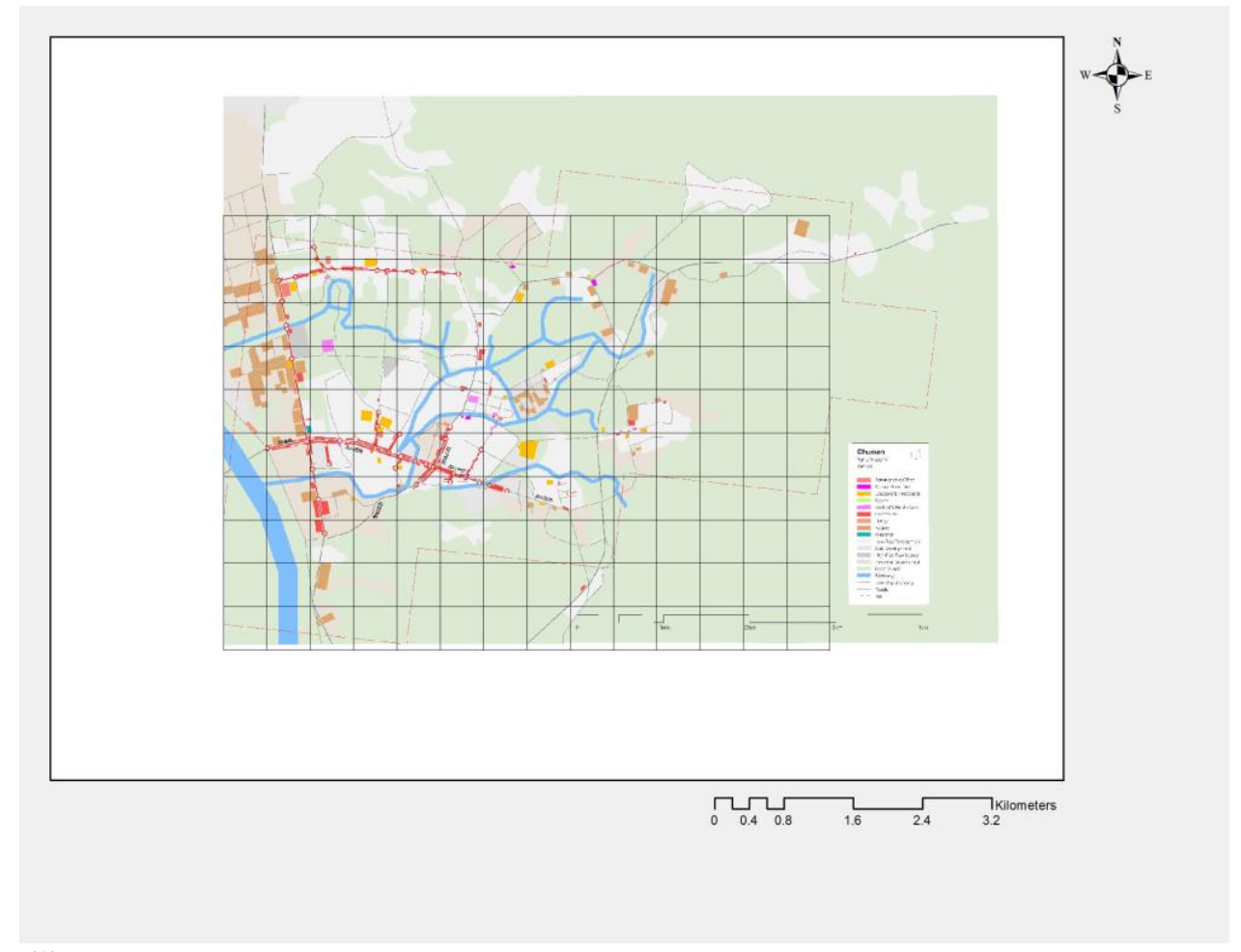

\section{Chumen}

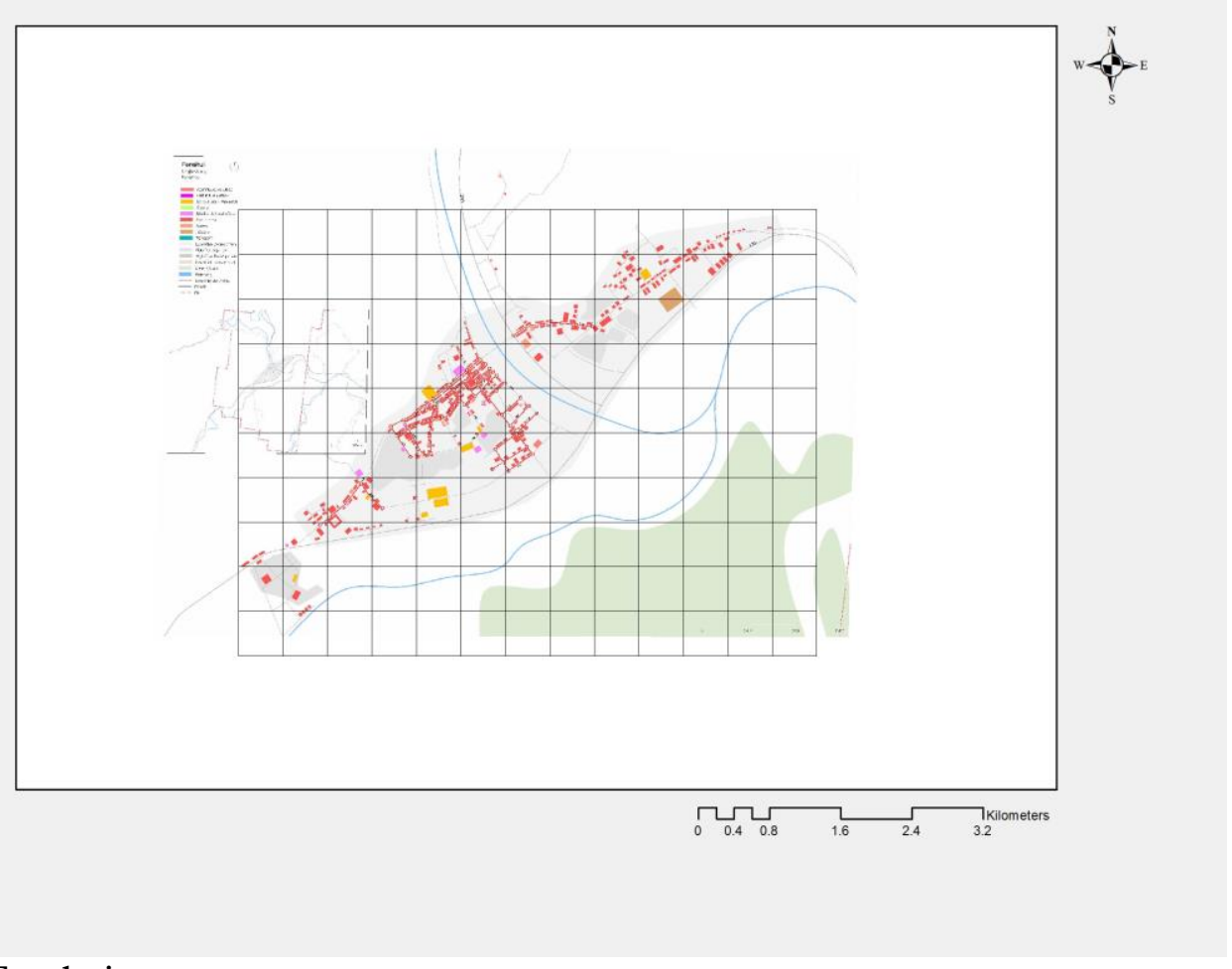

Fenshui 


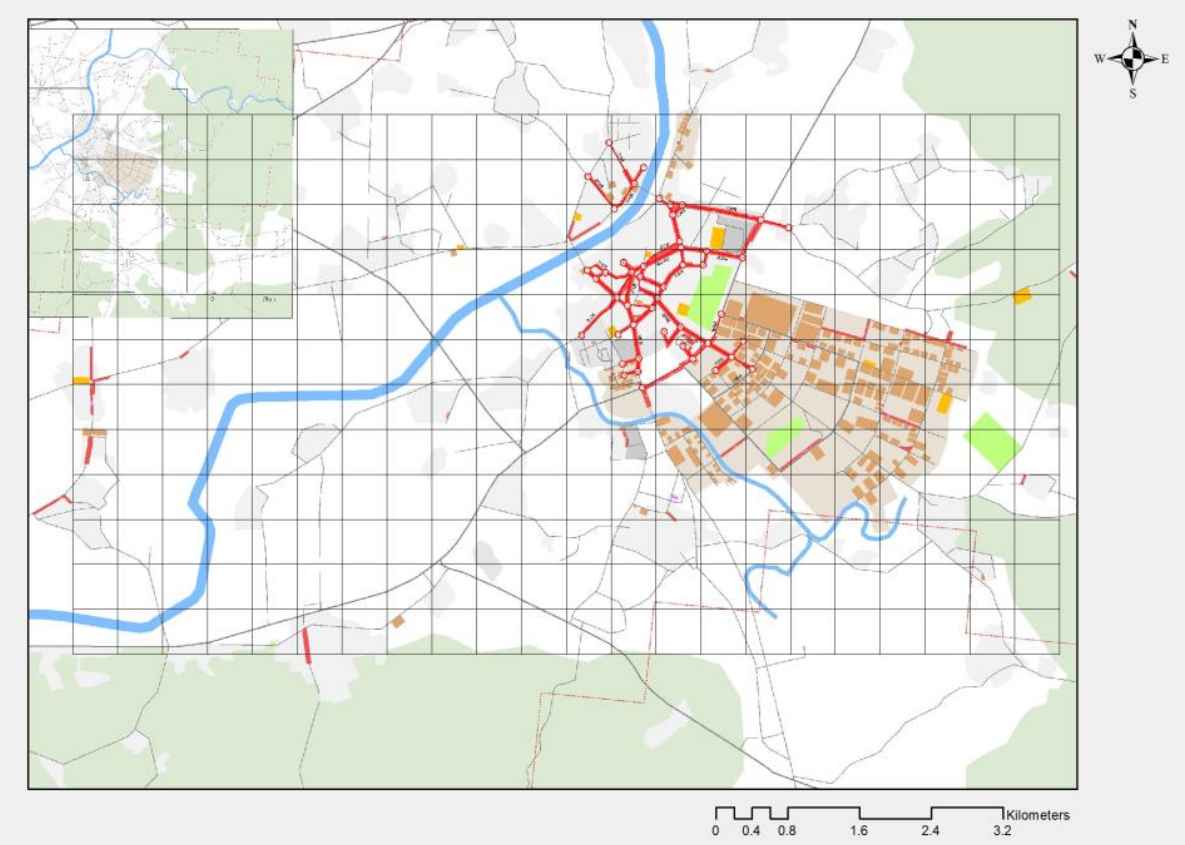

Fotang

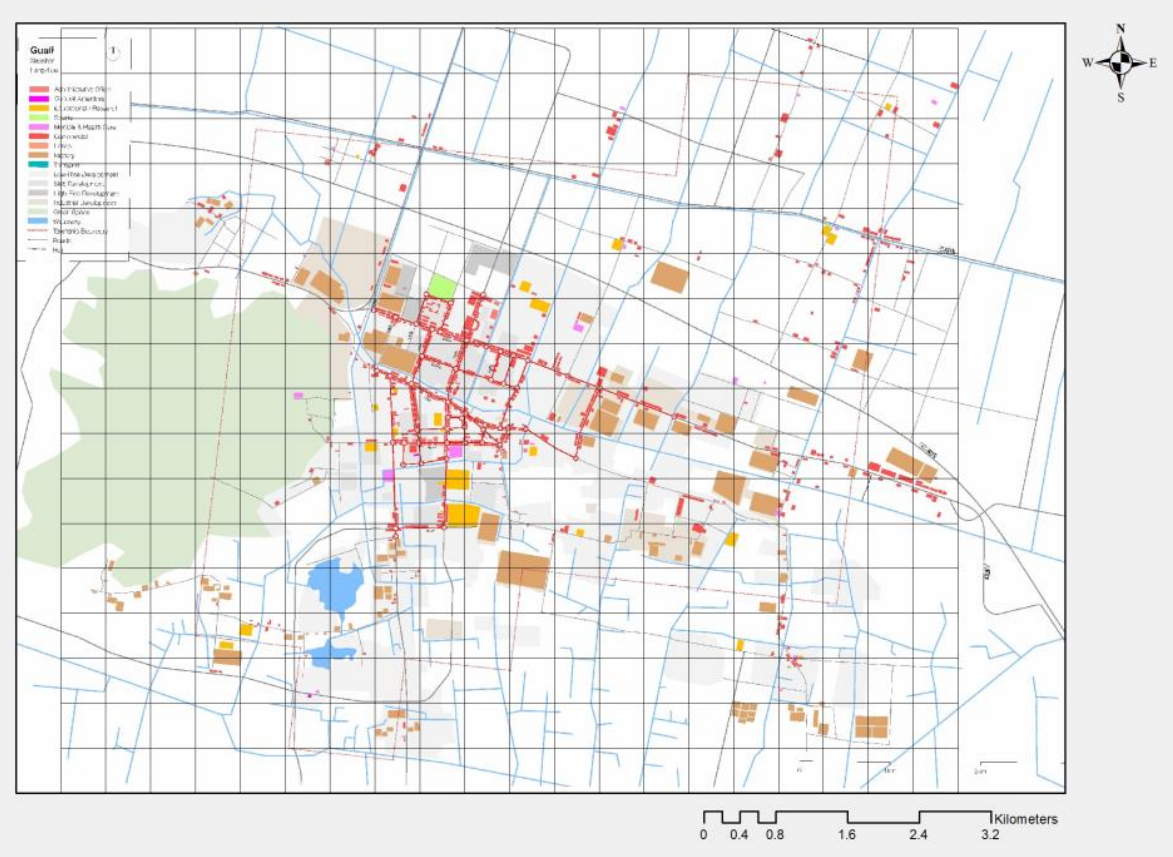

Guali 


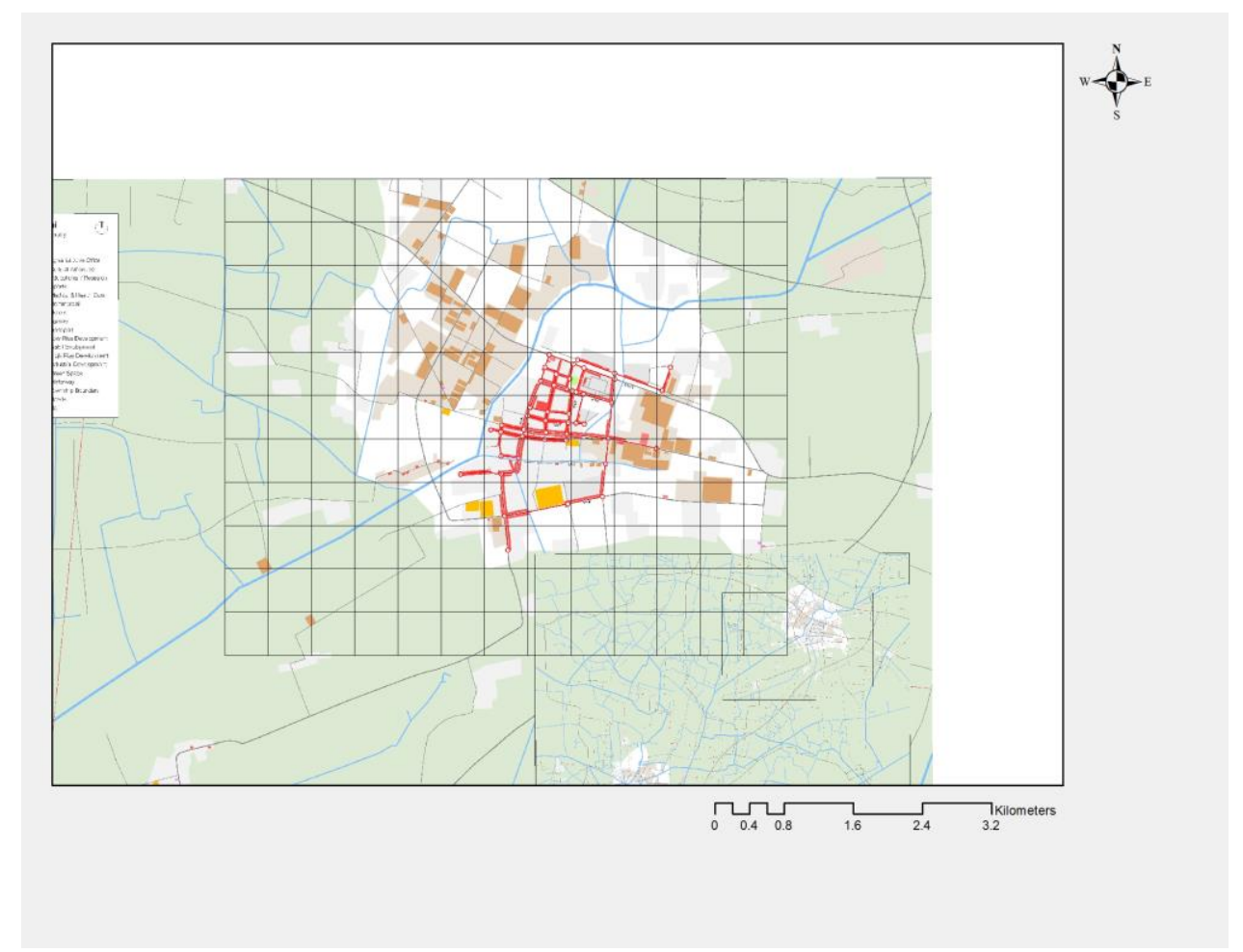

\section{Lianshi}

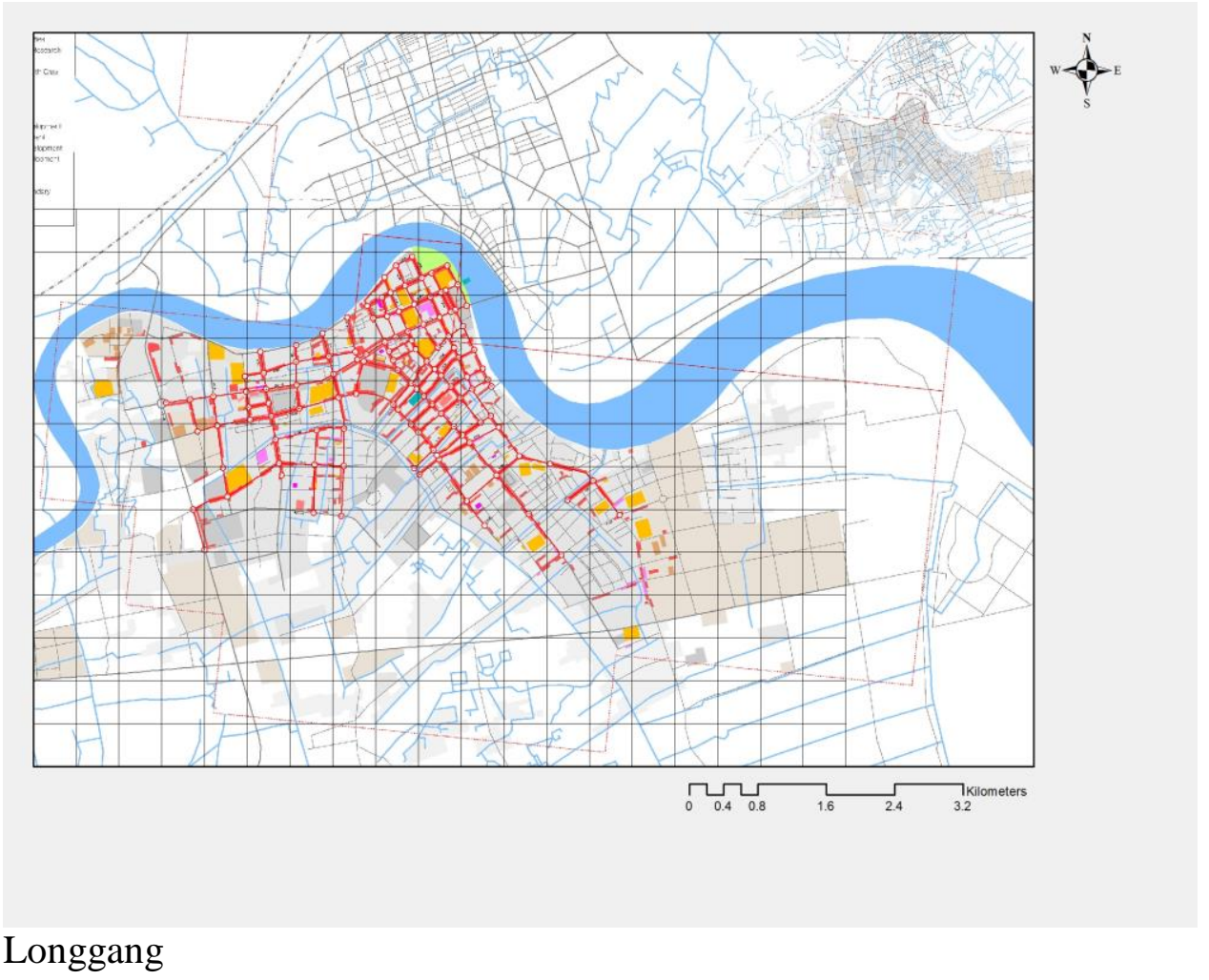




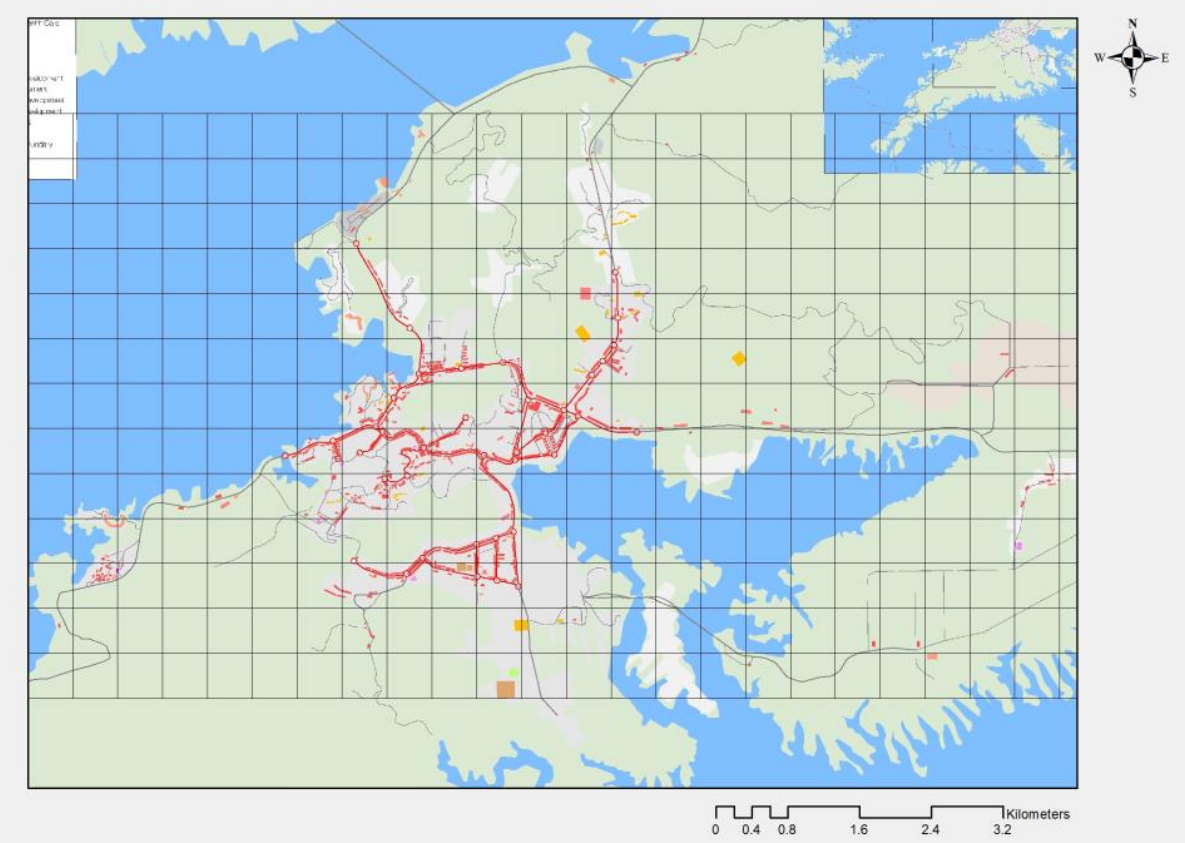

\section{Qiandaohu}

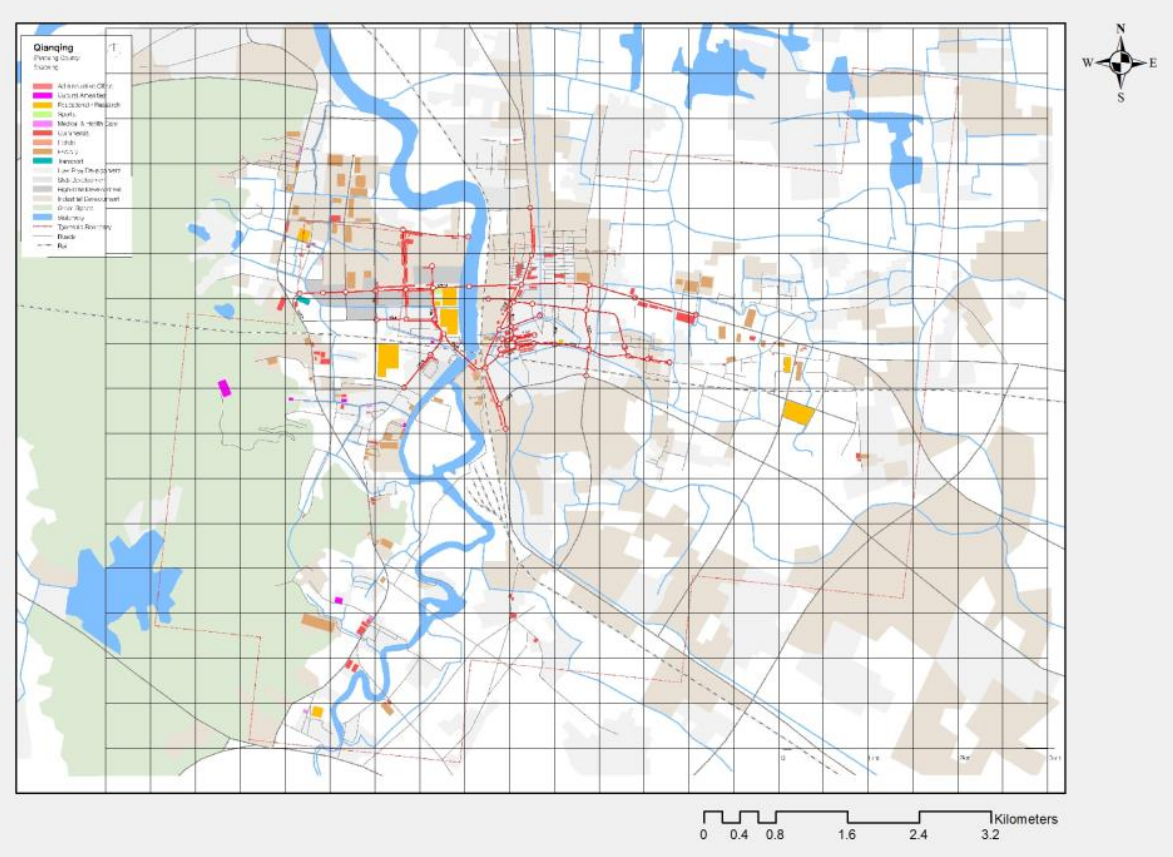

\section{Qianqing}




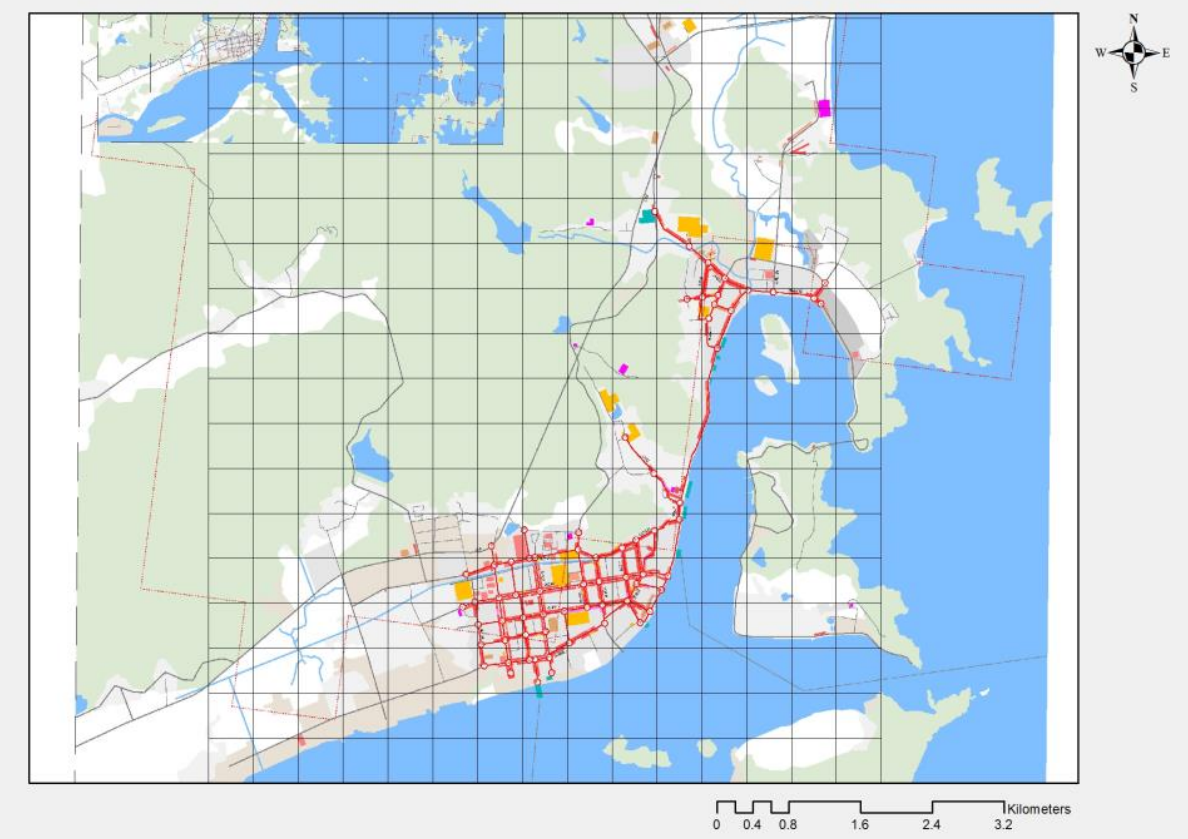

Shipu

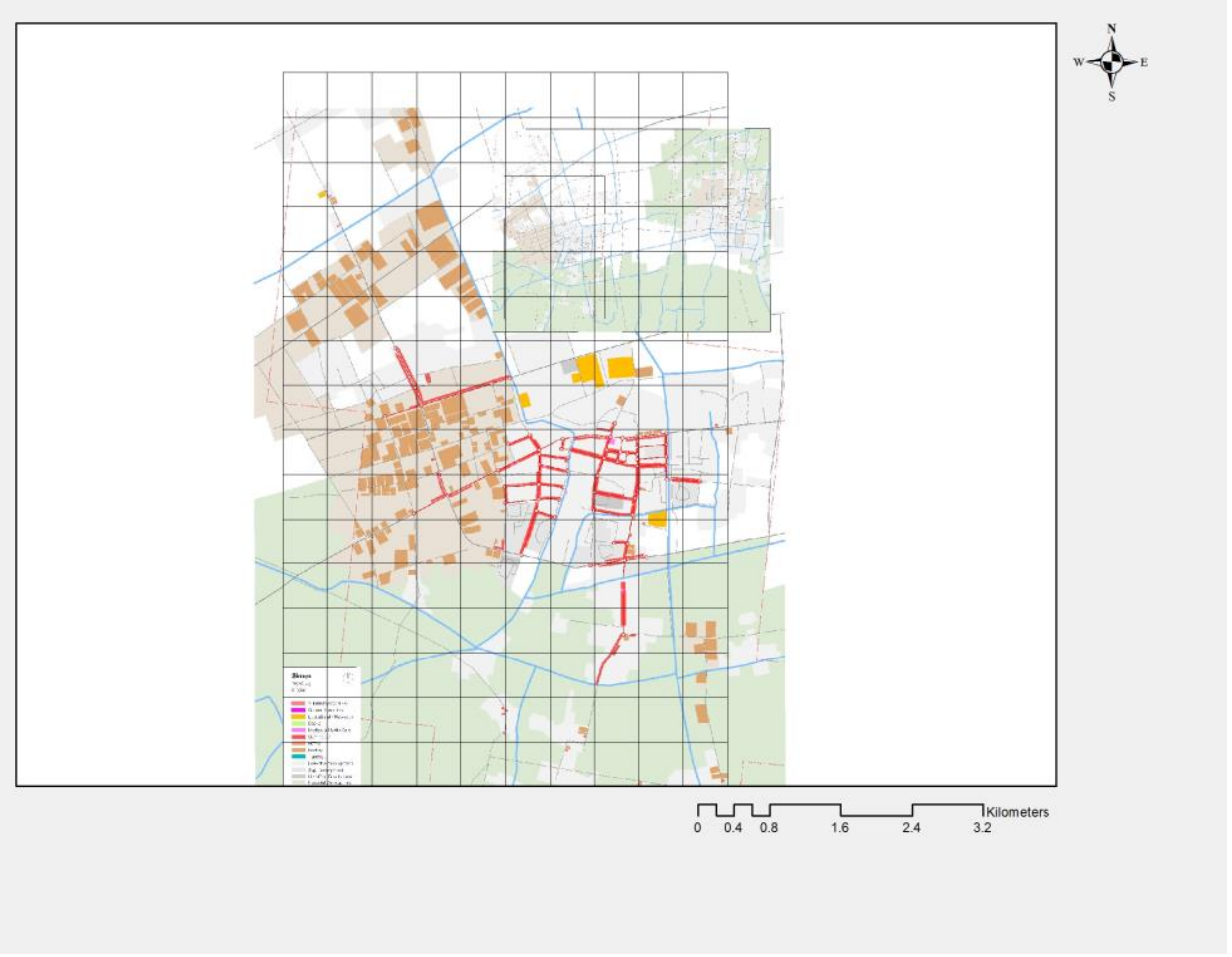

Simen 


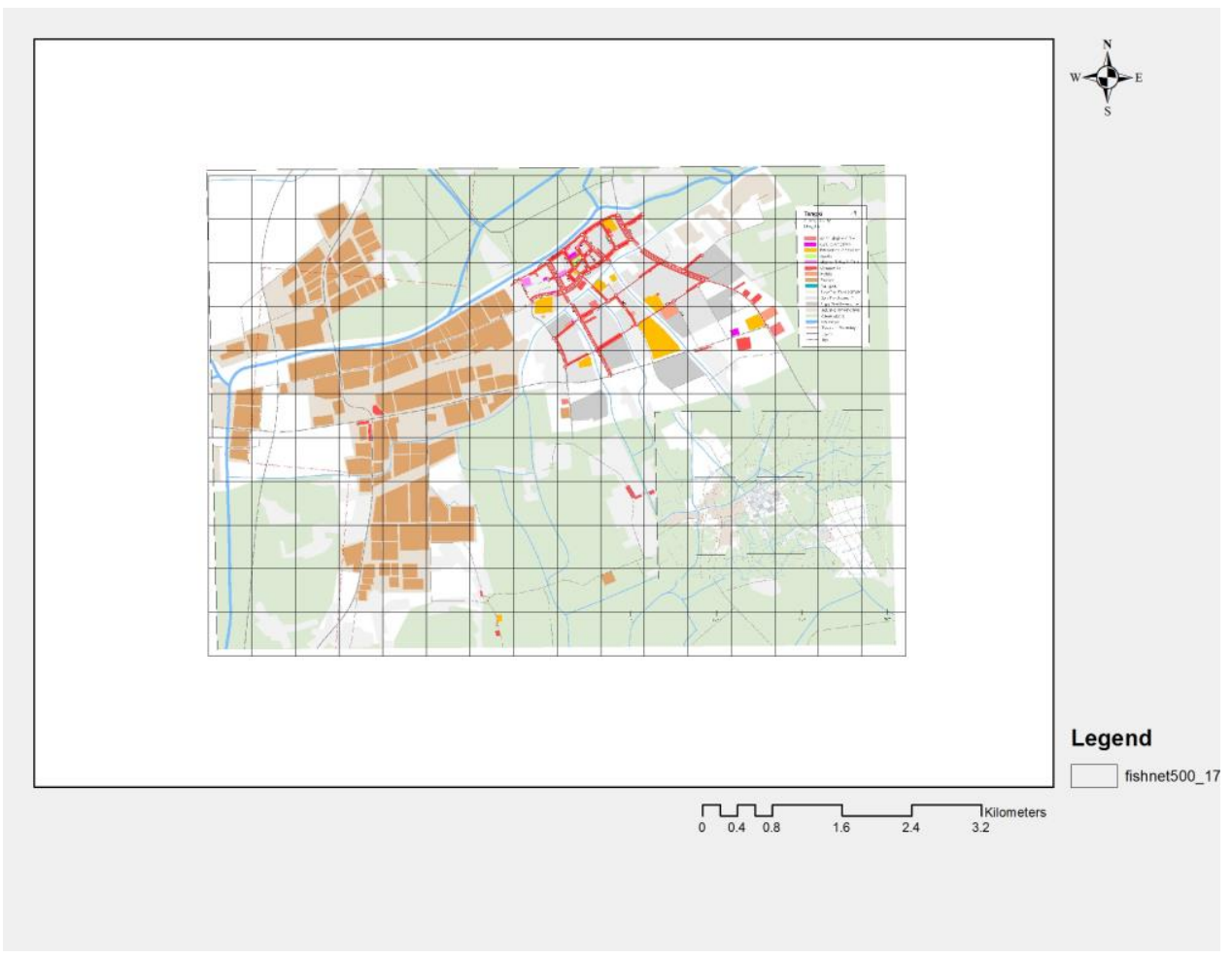

Tangqi

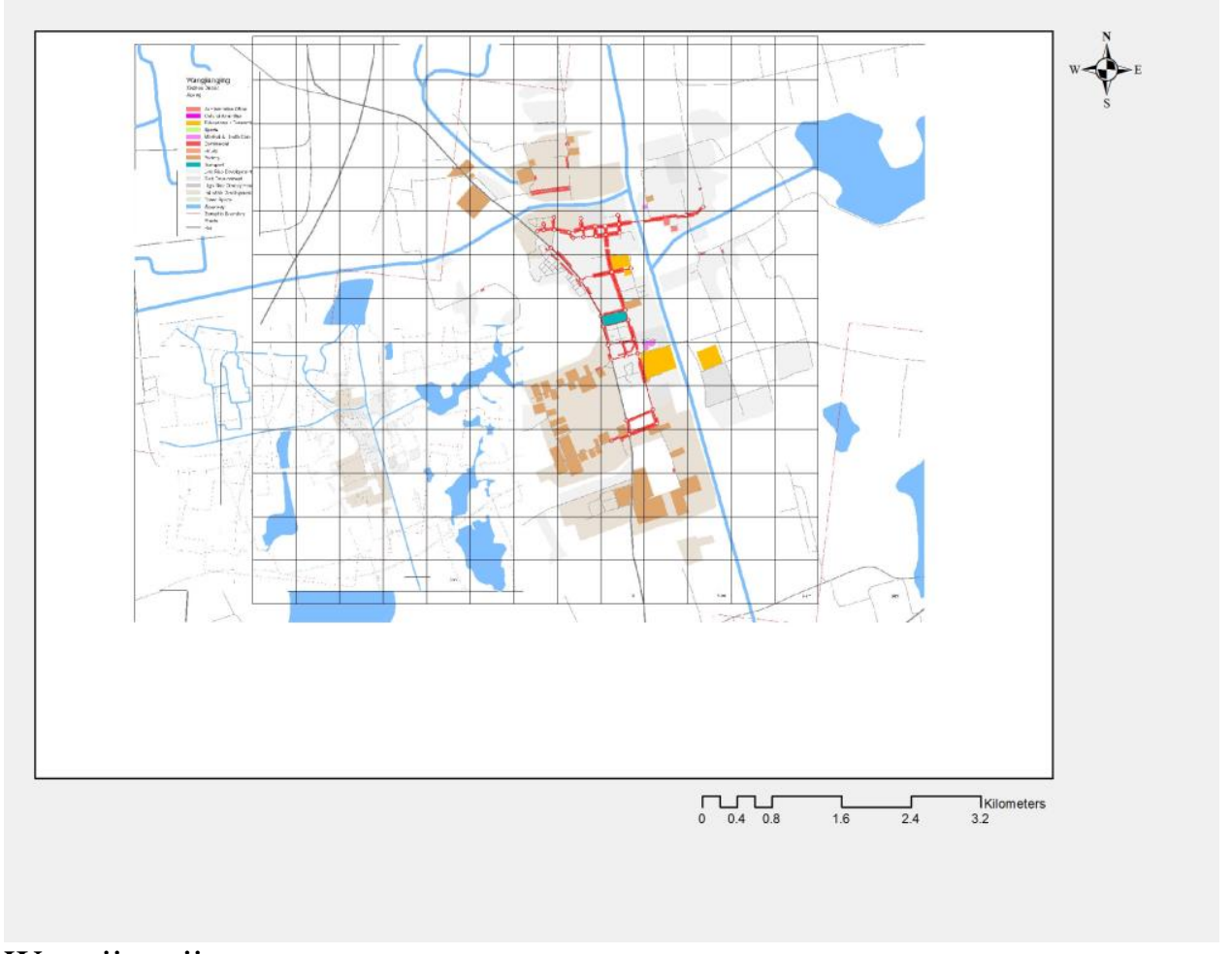

Wangjiangjing 


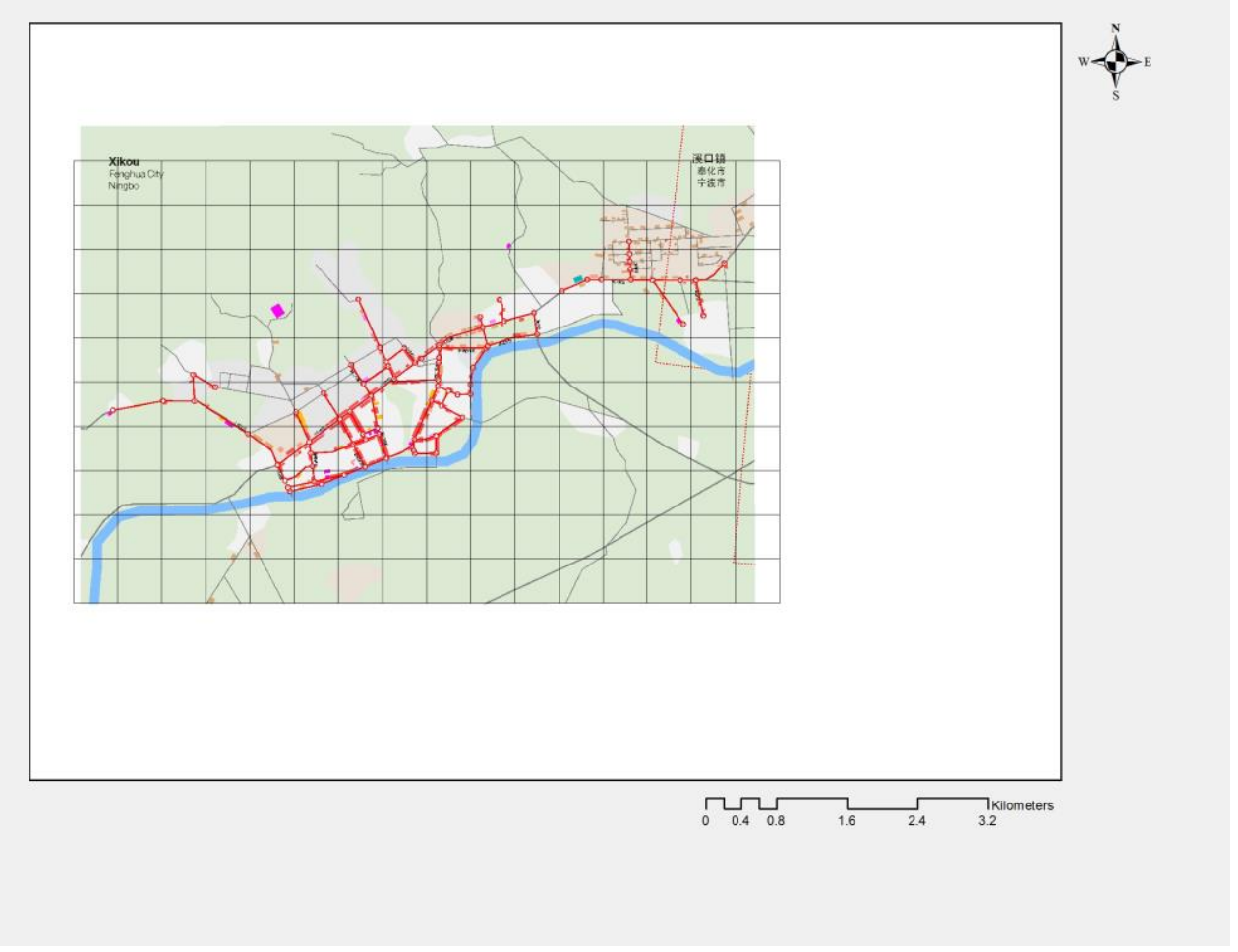

Xikou

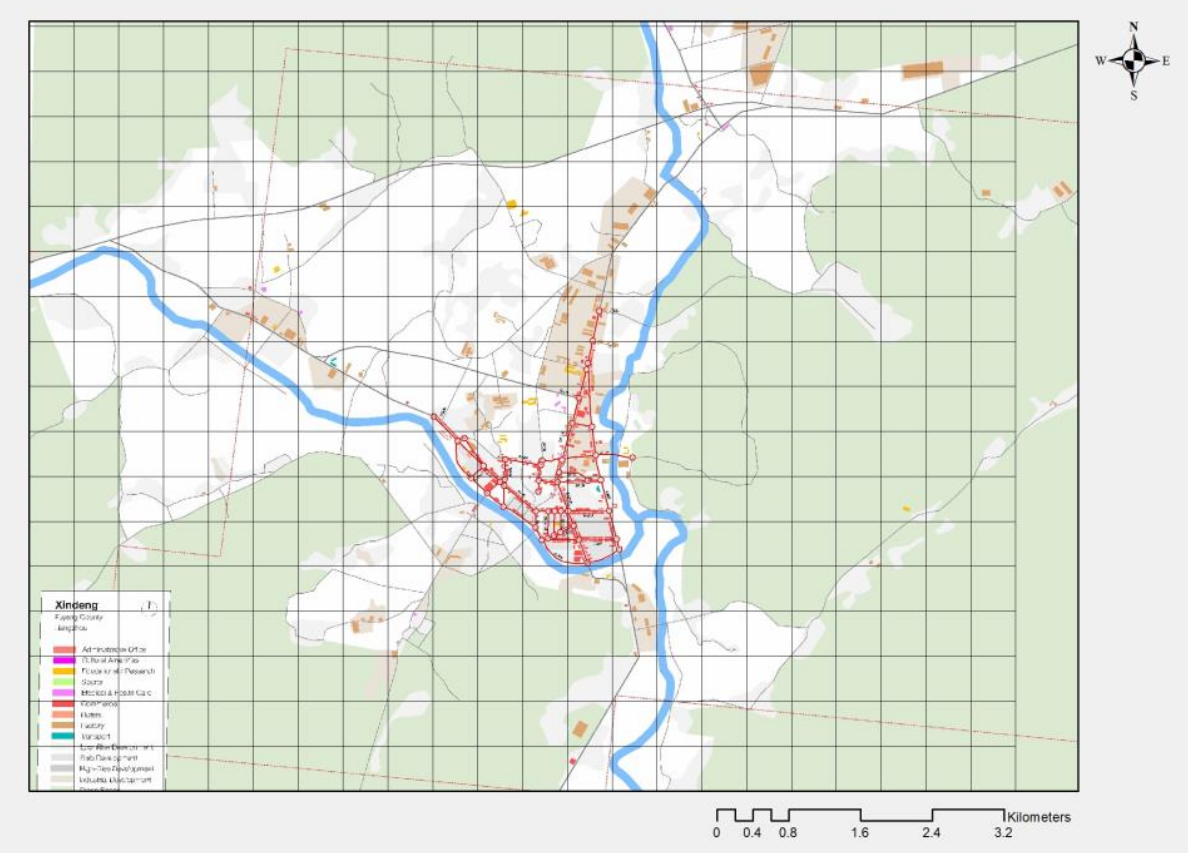

Xindeng 


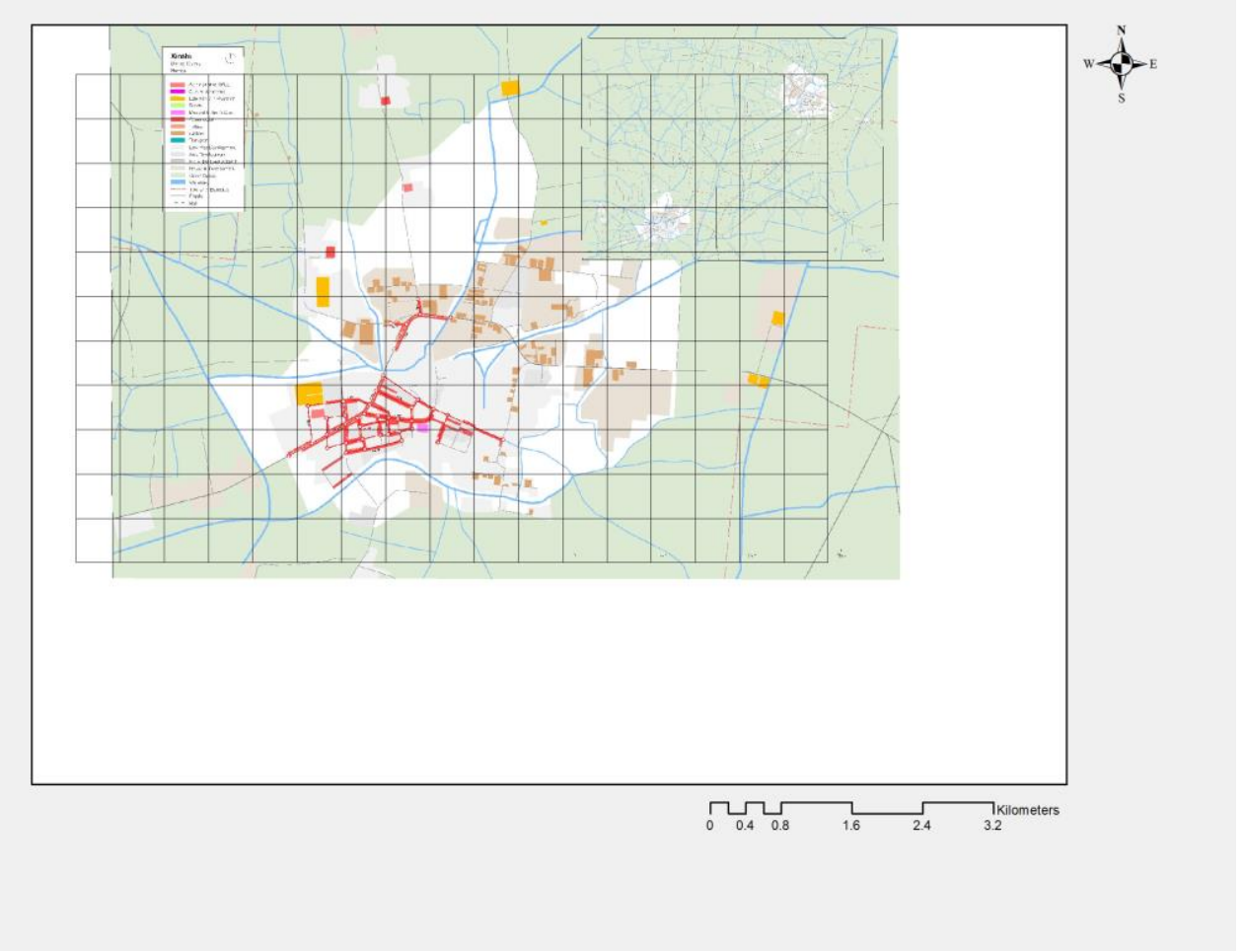

Xinshi
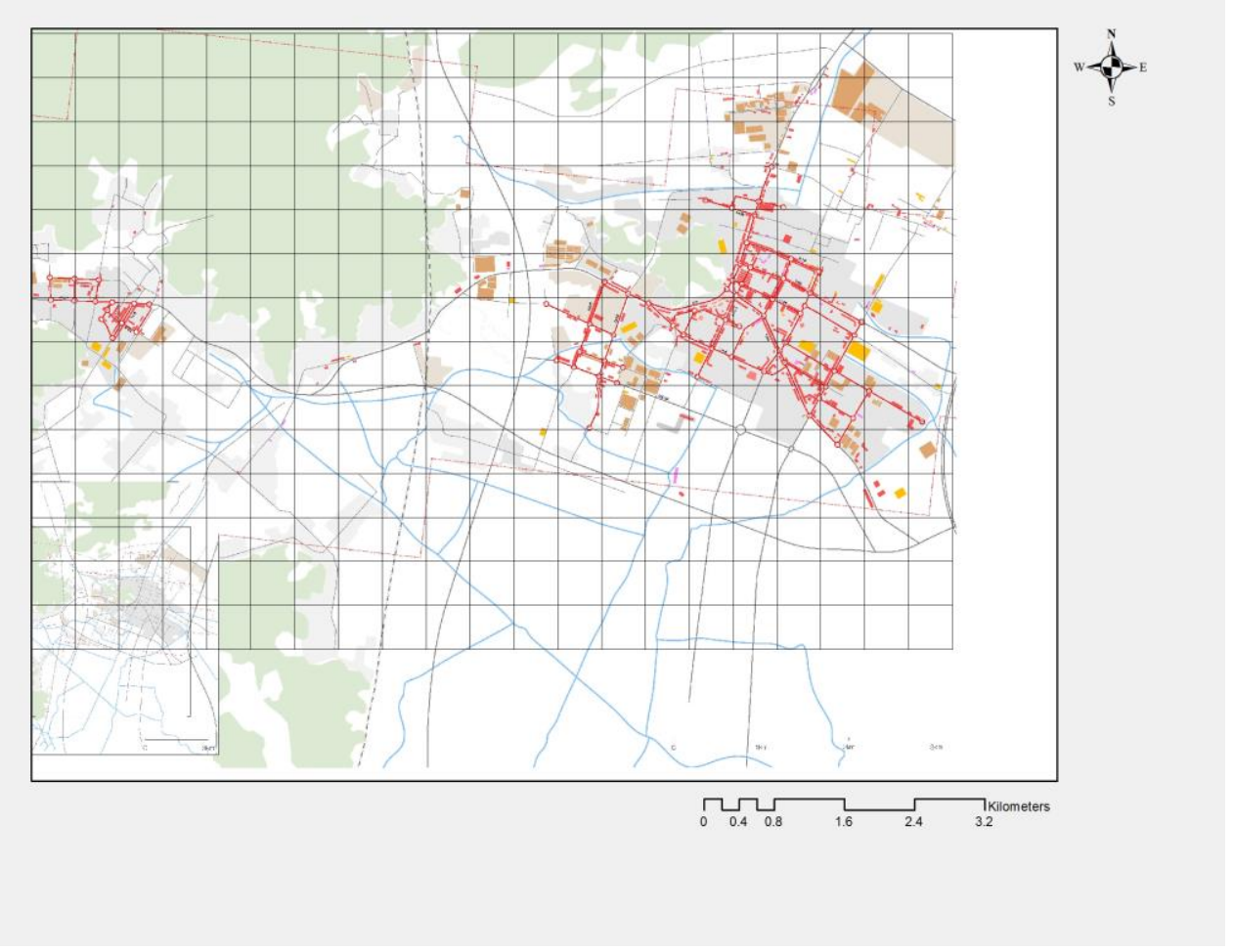

Zeguo 


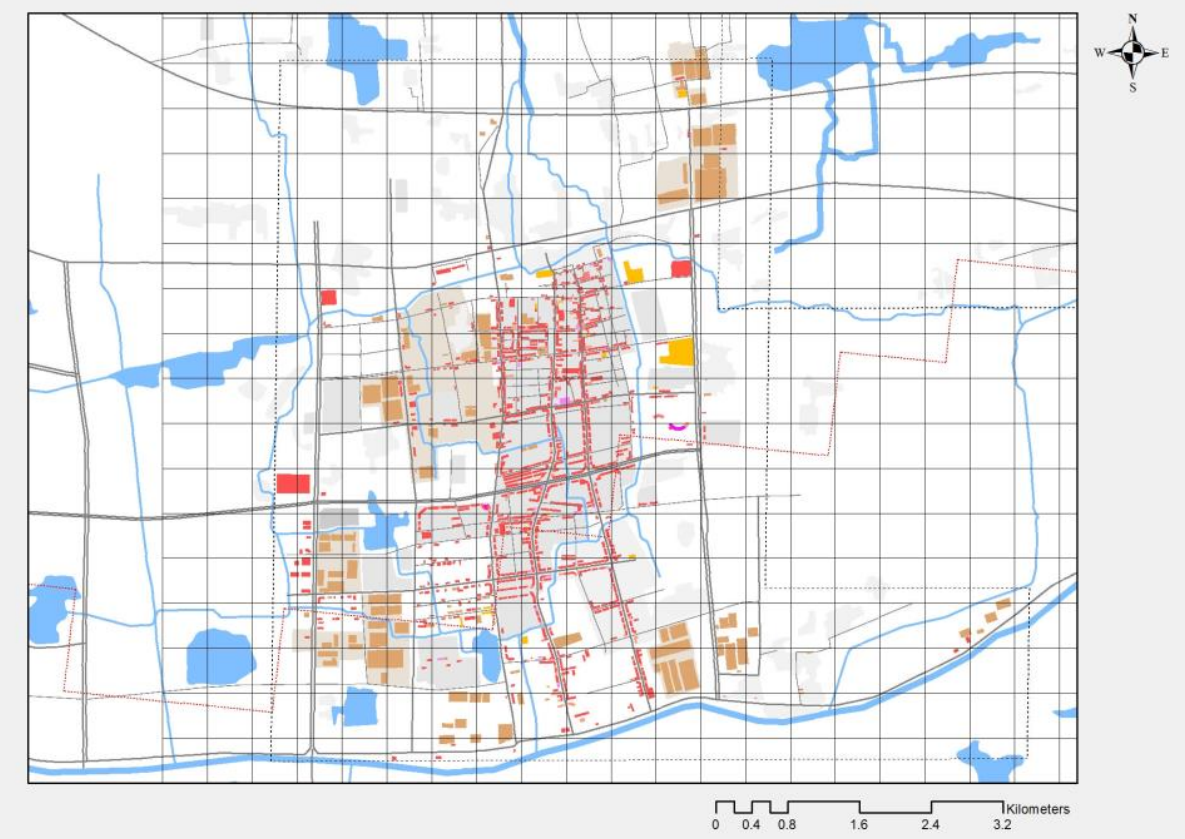

Zhili

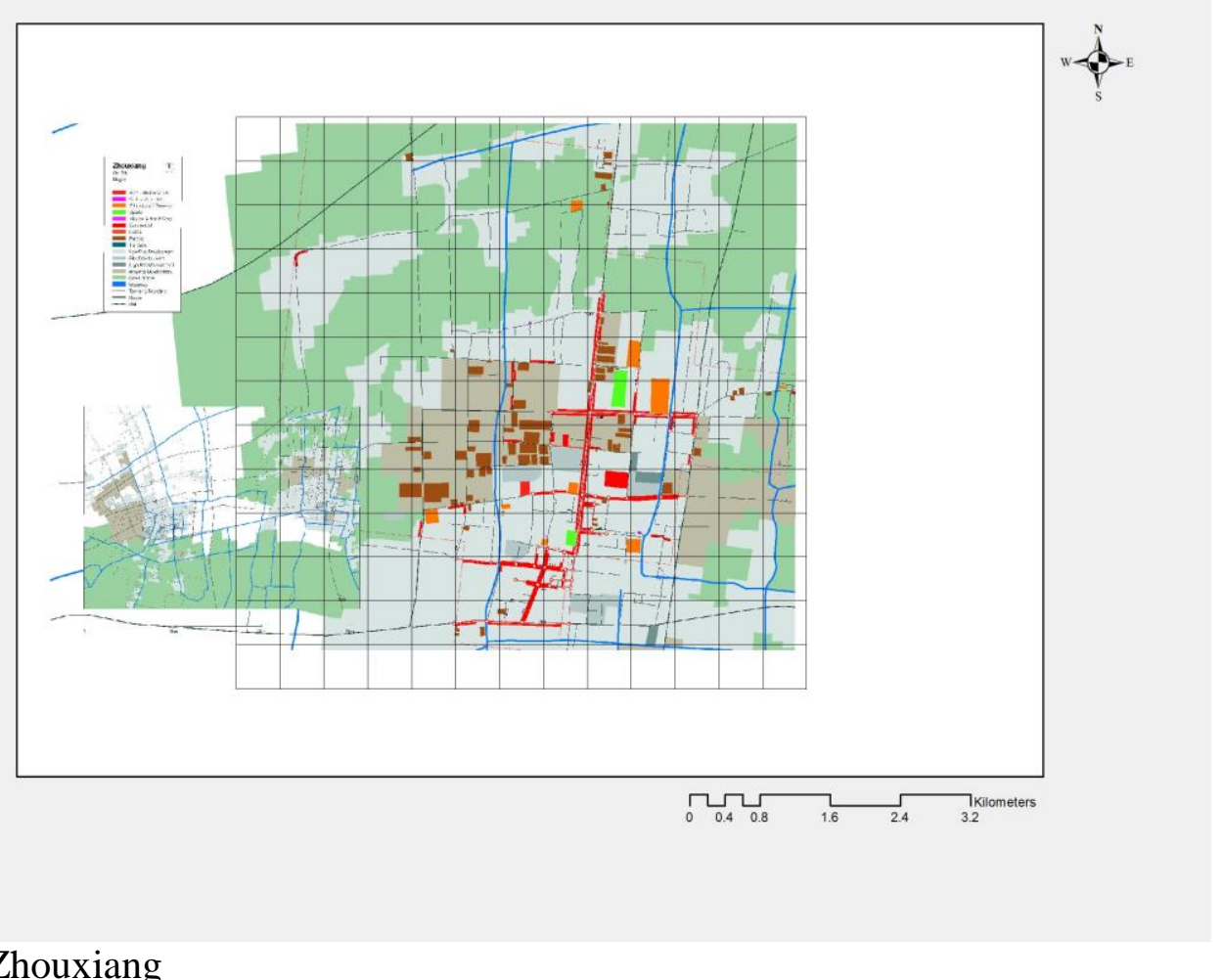

Zhouxiang

Appendix 1: 20 Towns selected study area 


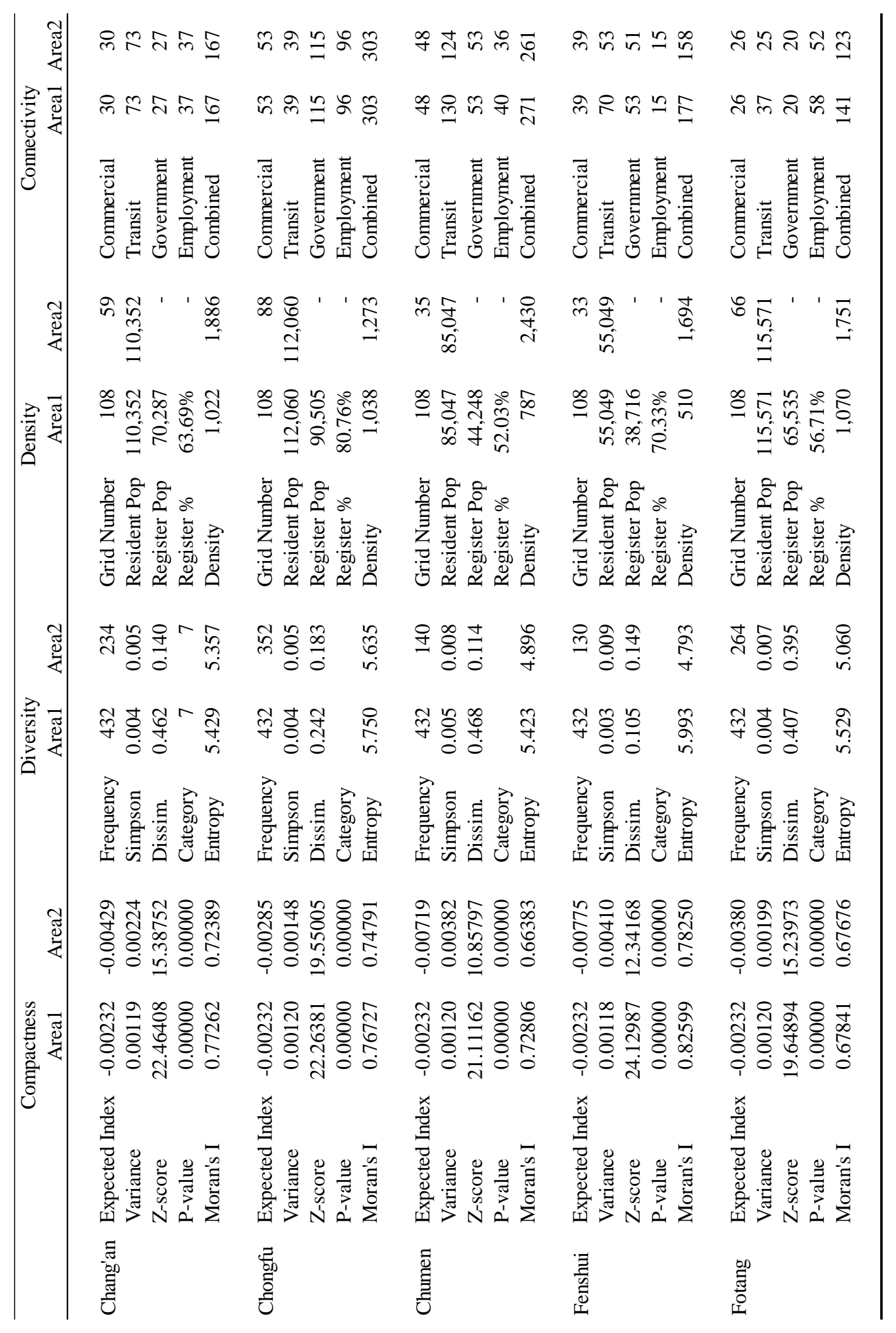

Appendix 2a: Measure of compactness, diversity, density, and connectivity for 20 towns in Zhejiang Province. 


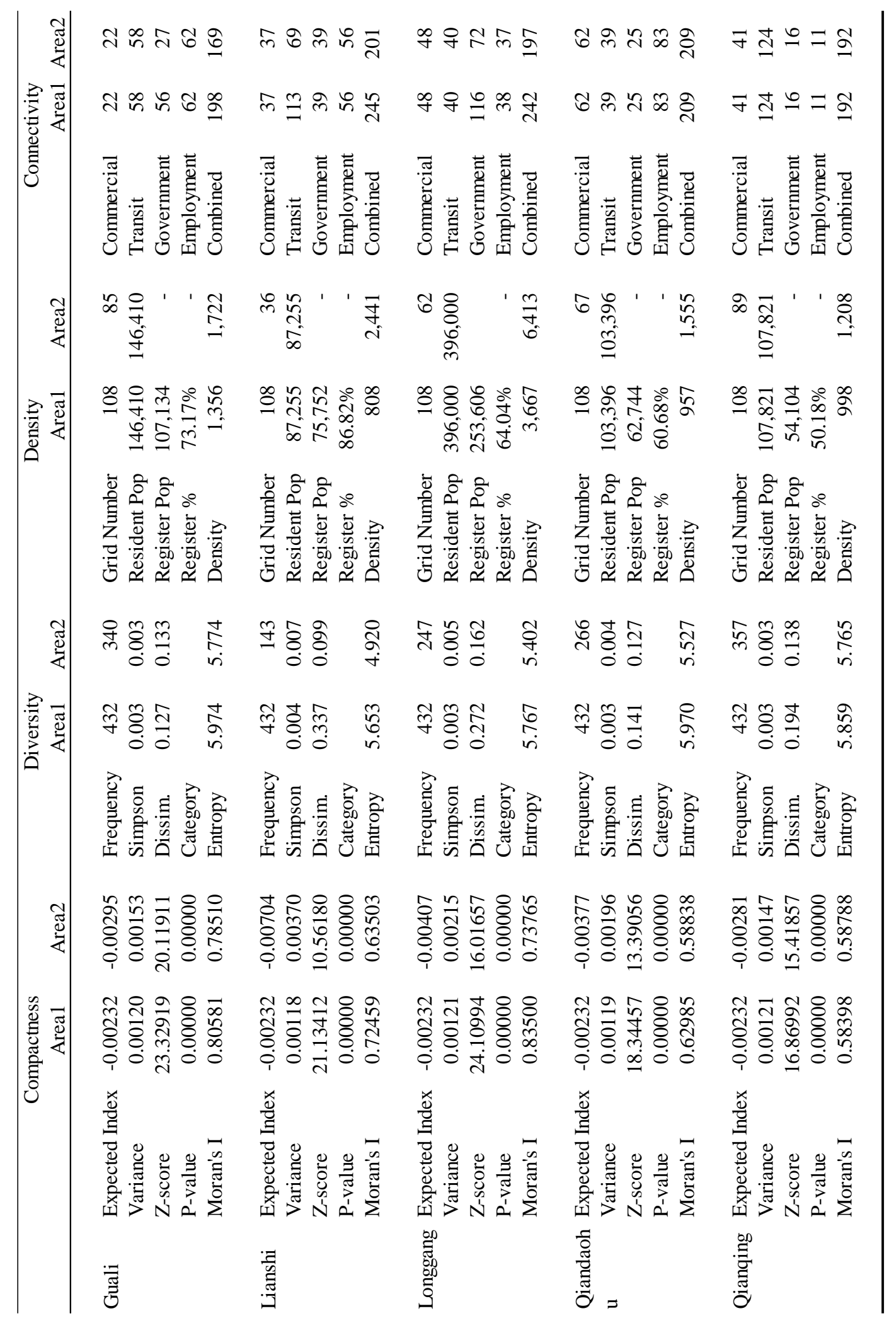

Appendix 2b: Measure of compactness, diversity, density, and connectivity for 20 towns in Zhejiang Province 


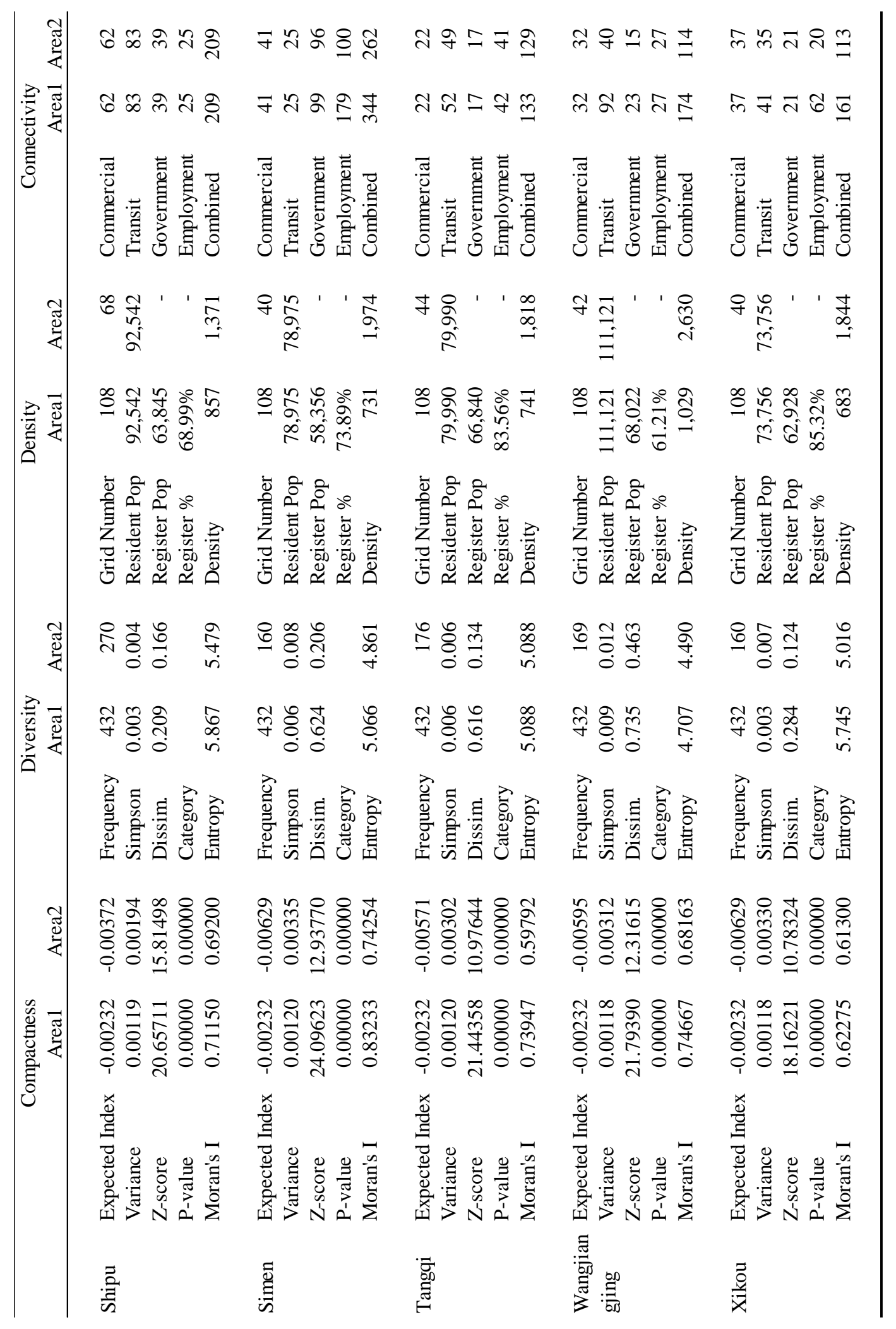

Appendix 2c: Measure of compactness, diversity, density, and connectivity for 20 towns in Zhejiang Province 


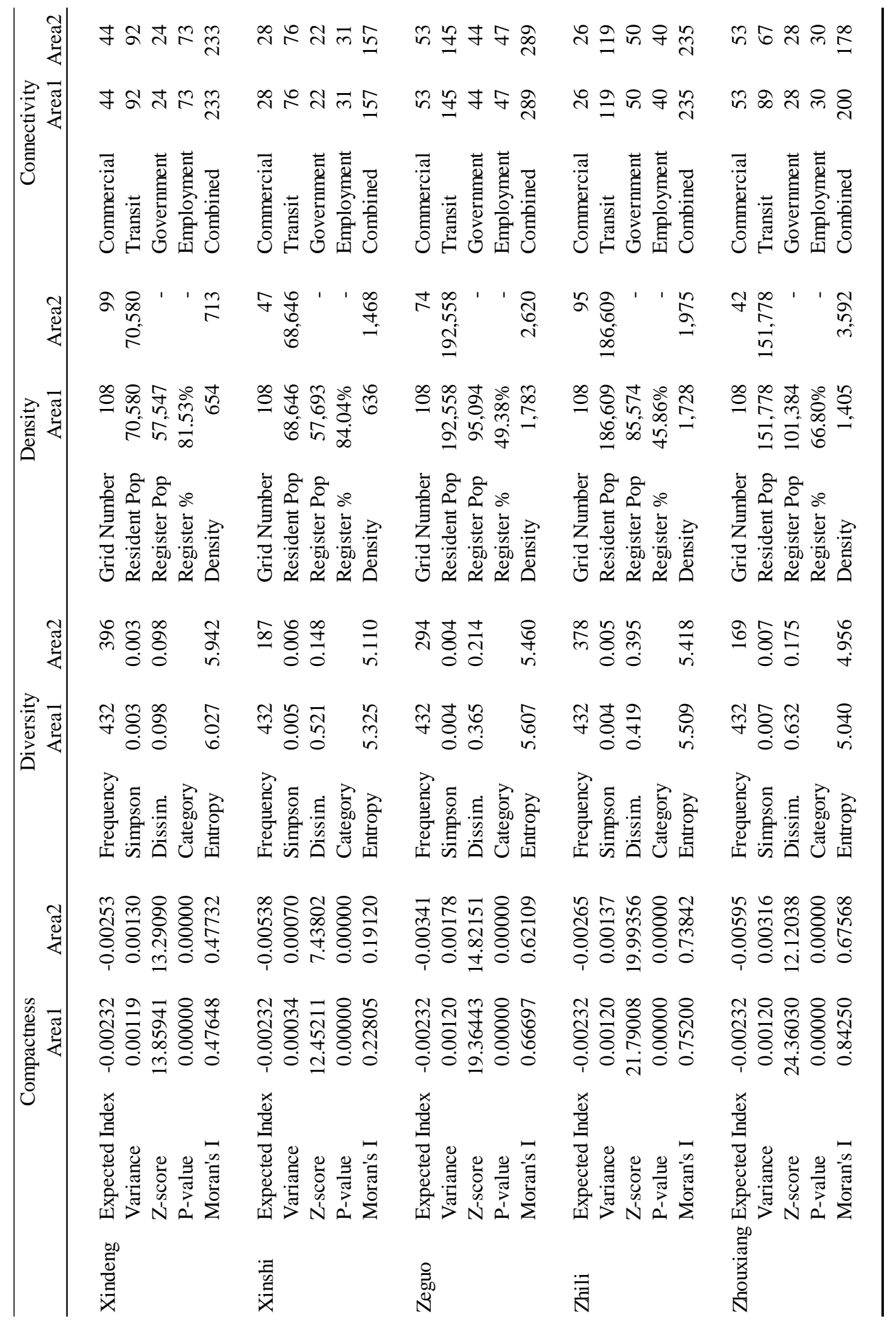

Appendix 2d: Measure of compactness, diversity, density, and connectivity for 20 towns in Zhejiang Province. Note: Area 1 contains an area which is universal in size and centered around each town. It was used conveniently for a quick comparison. Area 2, however, reflected the boundary and form of each town's specific urbanized condition. It was applied to evaluate the urban intensity measures selected in this paper. More explanations can be found in methodology section, paragraph one. 